\title{
MEMORANDUM
}

No 11/2015

\section{Did US Consumers 'Save for a Rainy Day' before the Great Recession?}

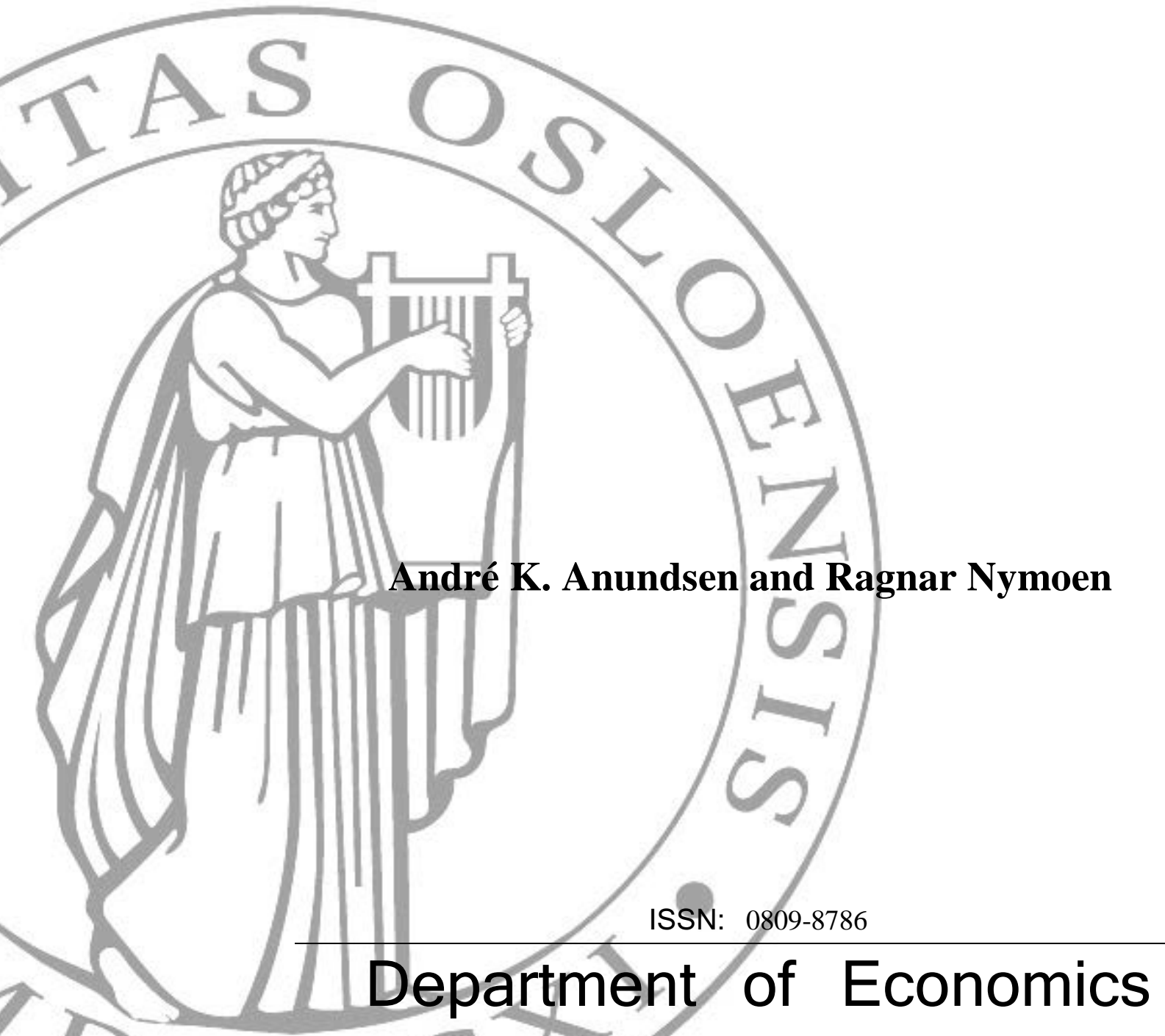


This series is published by the

\section{University of Oslo Department of Economics}

P. O.Box 1095 Blindern

N-0317 OSLO Norway

Telephone: + 4722855127

Fax: $\quad+4722855035$

Internet: http://www.sv.uio.no/econ

e-mail: econdep@econ.uio.no
In co-operation with

The Frisch Centre for Economic

\section{Research}

Gaustadalleén 21

N-0371 OSLO Norway

Telephone: +4722958820

Fax: $\quad$ +4722958825

Internet: $\quad$ http://www.frisch.uio.no

e-mail: $\quad$ frisch@frisch.uio.no

\section{Last 10 Memoranda}

\begin{tabular}{|c|c|}
\hline No $10 / 15$ & $\begin{array}{l}\text { Finn Førsun } \\
\text { Economic Perspectives on DEA }\end{array}$ \\
\hline No $09 / 15$ & $\begin{array}{l}\text { Andreas Kotsadam, Eivind Hammersmark Olsen, Carl Henrik Knutsen and } \\
\text { Tore Wig } \\
\text { Mining and Local Corruption in Africa }\end{array}$ \\
\hline No $08 / 15$ & $\begin{array}{l}\text { Eric Nævdal } \\
\text { Catastrophes and Expected Marginal Utility - How the Value of The Last } \\
\text { Fish in a Lak is Infinity and Why We Shouldn't Care (Much) }\end{array}$ \\
\hline No $07 / 15$ & $\begin{array}{l}\text { Niklas Jakobsson and Andreas Kotsadam } \\
\text { The Economics of Trafficking for Sexual Exploitation }\end{array}$ \\
\hline No $06 / 15$ & $\begin{array}{l}\text { Geir B. Asheim and Stéphane Zuber } \\
\text { Evaluating Intergenerational Risks: Probability Adjusted Rank-Discounted } \\
\text { Utilitarianism }\end{array}$ \\
\hline No $05 / 15$ & $\begin{array}{l}\text { Fridrik Mar Baldursson and Nils-Henrik von der Fehr } \\
\text { Natural Resources and Sovereign Expropriation }\end{array}$ \\
\hline No $04 / 15$ & $\begin{array}{l}\text { Erik Biørn and Xuehui Han } \\
\text { Persistence, Signal-Noise Pattern and Heterogeneity in Panel Data: With } \\
\text { an Application to the Impact of Foreign Direct Investment in GDP }\end{array}$ \\
\hline No $03 / 15$ & $\begin{array}{l}\text { Alice Ciccone } \\
\text { Environmental Effects of a Vehicle Tax Reform: Empirical Evidence from } \\
\text { Norway }\end{array}$ \\
\hline No $02 / 15$ & $\begin{array}{l}\text { Katinka Holtsmark and Kristoffer Midttømme } \\
\text { The Dynamics of Linking Permit Markets }\end{array}$ \\
\hline No $01 / 15$ & $\begin{array}{l}\text { Francesco Lania and Alessia Russo } \\
\text { Public Education and Pensions in Democracy: A Political Economy } \\
\text { Theory }\end{array}$ \\
\hline
\end{tabular}

Previous issues of the memo-series are available in a PDF® format at: http://www.sv.uio.no/econ/english/research/unpublished-works/working-papers/ 


\title{
Did US consumers 'save for a rainy day' before the Great Recession?*
}

\author{
André K. Anundsen \\ Norges Bank \\ Ragnar Nymoen \\ Economic Analysis Norway - Center for Wage formation and University of Oslo
}

\section{Memo 11/2015-v1}

This version May 8, 2015

\begin{abstract}
The 'saving for a rainy day' hypothesis implies that households' saving decisions reflect that they can (rationally) predict future income declines. The empirical relevance of this hypothesis plays a key role in discussions of fiscal policy multipliers and it holds under the null that the permanent income hypothesis is true. We find mixed support for this hypothesis using time series data for the 100 largest US Metropolitan Statistical Areas, as well as aggregate macro time series, for the period 1980q1-2011q4. That is, income is more often found to predict consumption and saving than the converse. Our modus operandi is to investigate the 'saving for a rainy day' hypothesis by testing (weak) exogeneity of income and consumption and by exploring the direction of Granger causality between the two series. We also give evidence that house price changes played a role in the US income and consumption dynamics, before, during and after the Great Recession.
\end{abstract}

Keywords: Cointegration; Consumption; Granger causality; Permanent income hypothesis; Household saving

JEL classification: C22; C32; C51; C52; E21; E62

*This Working Paper should not be reported as representing the views of Norges Bank. The views expressed are those of the authors and do not necessarily reflect those of Norges Bank. The paper was presented at the conference "Econometric Modelling in a Rapidly Changing World" in Oxford, September 2014, at the 2014 European Winter Meeting of the Econometric Society in Madrid, December 2014, at the $37^{\text {th }}$ Annual Meeting of the Norwegian Economic Association in Bergen, January 2015, at the $23^{r d}$ Symposium of the Society for Nonlinear Dynamics and Econometrics in Oslo, March 2015, and at seminars and workshops in the Central Bank of Hungary, Norges Bank [Central Bank of Norway] and Statistics Norway. We are grateful to the participants at these events for their comments. We would also like to thank Farooq Akram, Bruce Hansen, Veronica Harrington, Tord Krogh and Asbjørn Rødseth for comments and discussions. All results may be reproduced using an Ox-code that will be made available on the authors' websites. Contact details: André Kallåk Anundsen: Norges Bank Research, Norges Bank, Bankplassen 2, P.O. Box 1179 Sentrum, NO-0107 Oslo, Norway. Email: andre-kallak.anundsen@norgesbank.no. Ragnar Nymoen: Department of Economics, University of Oslo, PO Box 1095 Blindern, N-0317 Oslo. Email: ragnar.nymoen@econ.uio.no.n 


\section{Introduction}

Consumer expenditure is by far the largest component of spending in the US economy, and in most other countries as well. Not surprisingly, the study of saving and consumption dynamics is therefore of great importance both for economic policy analysis and economic forecasting. It is well known that the rational expectations permanent income hypothesis (PIH hereafter) due to Hall (1978) is consistent with non-stationarity of income and stationarity of saving, see e.g. Muellbauer and Lattimore (1995, Ch.3.2). When combined with the famous theoretical result of Hall (1978), stating that consumption follows a first order Markov process, we obtain the implication that causation runs from lagged saving to current income and not from saving to consumption. In this paper, we test the direction of causation between consumption and income using quarterly time series data for the 100 largest US Metropolitan Statistical Areas (MSAs), as well as aggregate macro data, over the period 1980q1-2011q4.

A common ground is represented by the idea that the savings rate may be a stationary variable, even though there are stochastic trends in the time series of both income and consumption. This common ground allows the analysis to be held within a vector autoregressive (VAR) framework. To account for the stochastic trends in income and consumption, we apply econometric methods that are robust to the non-stationarity of the two series, i.e. the cointegrated VAR model of Johansen (1988, 1995). Under the null that the statistical relationship between consumption and income describes the PIH, a fall in saving anticipates a future increase in income and a rise in saving anticipates future income declines, Campbell (1987). 1 This also explains why the result has been dubbed the 'saving for a rainy day' hypothesis, cf. Attanasio (1999).

In his seminal paper, Campbell (1987) referred to (Granger) causation running from the savings rate to income growth - and not the other (Keynesian) way around - as the weak implication of the permanent income hypothesis. Empirically, using aggregate US

\footnotetext{
${ }^{1}$ Campbell showed this for an infinitely lived consumer with quadratic utility function, equal and constant subjective discount rates and no credit constraints.
} 
data for the period 1953-1984, Campbell found that the implication of the PIH for the direction of Granger causality preserved even if other implications of the PIH fared less well empirically: $\left.\right|^{2}$ The conclusion that the PIH is only partly correct, and that it needs to be supplemented by several factors to account for the many features of consumption dynamics that we are trying to understand, is consistent with the consensus view in modern macroeconomics, see e.g. Romer (2006), Carroll (2009), Jappelli and Pistaferri (2010) and Attanasio and Weber (2010).

Although one-way Granger causality from (the log of) the average propensity to consume to income growth can be regarded a weak implication of the PIH, it has strong implications for the analysis of the income and job recession that followed in the wake of the global financial crisis. For example, the increase in the savings rate preceding the drop in income growth in 2008 and 2009 seems to corroborate the PIH Granger-causality predictions, meaning that consumers had started to adapt to a period with low income growth that they were able to rationally foresee. However, several months earlier real house prices had peaked and started to fall, meaning that the increase in saving that went before the fall in income may have signaled the start of a period of financial consolidation in the US household sector. In that interpretation, the increase in saving may have added to the income recession by depressing aggregate demand.

Using time series data spanning the period 1980q1-2011q4, both for the 100 largest US MSAs and for the aggregate US economy, our modus operandi is to test the implied VAR parameter restrictions of the PIH, as outlined in Campbell (1987). Thus, in addition to replicating the aggregate analysis in Campbell (1987) on a sample covering both the Great Moderation and the Great Recession, we consider disaggregate data for 100 regional US markets. Further, our analysis allow us to shed light on the role of house prices for consumption dynamics before, during and after the Great Recession. More precisely, we estimate separate cointegrated VAR models in consumption, income, house prices and the real interest rate for all 100 MSAs. Thus, we allow for complete heterogeneity in lag ${ }^{2}$ Campbell (1987, p.1267). 
length and both short and long-run parameters. Tests for the VAR restrictions implied by the PIH are then conducted for each of the 100 MSAs.

The conclusions from the MSA level and the aggregate analyses are similar, and results from the 1980q1-2007q4 Great Moderation sub-sample strongly suggest that income is causing consumption, while there is mixed support for causation running in the other direction. Including the financial crisis period in our sample strengthens these result, and overall our findings lead us to reject the 'saving for a rainy day' hypothesis. Interestingly, our results suggest a strengthened effect of house prices on consumption dynamics after the financial crisis. This suggests that US consumers who saw their retirement funds saved up in the housing market completely wiped out during the housing bust increased their saving to compensate for this loss.

Our findings that the importance of house prices for consumption dynamics has increased in the aftermath of the subprime crisis suggests that the spike in the savings rate following the recent financial crisis may - at least partly - be attributed to a financial consolidation effect. This finding adds insight to the already large literature attempting to explain the puzzle that household saving declined during the Great Moderation. A branch of this literature suggests the easing of credit conditions as an explanation, see e.g. Parker (2000) and Aron et al. (2012). Further, Guerrieri and Lorenzoni (2011), Eggertsson and Krugman (2012) and Hall (2011) find that the tightening of credit standards in the period succeeding the Great Recession can explain the sharp increase in the savings rate. An alternative explanation was highlighted in an earlier contribution by Carroll (1992), who suggested precautionary saving as a an explanation for why savings rates tend to increase in recession periods. A more recent study by Alan et al. (2012) reaches a similar conclusion. A final explanation is that the evolution of the savings rate is driven by changes in households' net worth. Consistent with this view, Mian et al. (2013) estimate a sizeable marginal propensity to consume out of housing net worth using US zip code level data for the 2006-2009 period. In a recent paper, Carrol et al. (2012) investigate the relative importance of credit conditions, precautionary saving and 
the wealth channel in explaining US savings rate dynamics. While their results suggest that all three channels are important, they find that the largest contributor to the recent increase in the savings rate is the drop in household wealth. Our findings are consistent with the view in Carrol et al. (2012) and Mian et al. (2013).

There is a possibility that households living through a financial crisis adjust their savings rate upwards relative to what they would have done otherwise. This would be consistent with history dependent dynamics, e.g., in the form of the cumulative prospect theory of Tversky and Kahneman (1992), stating that extreme events change the weights that agents put on the probabilities of future economic fortunes and misfortunes. In the case of this type of behavioral change, financial consolidation may mark the start of a secular rise in saving, since the behavior of the cohorts that become exposed to a crisis will continue to influence the aggregate for many years to come. However, as documented empirically by Aizenman and Noy (2013), the consequences of economic disasters on household saving probably depends on the degree of perceived political risk as well, which can of course work both ways.

The findings in this paper also relates to the discussion about the role of expansionary fiscal policy during the jobs and incomes crisis that followed the financial crisis, cf. DeLong and Summers (2012), Eberly (2014) and Stiglitz (2014). The size of the fiscal multiplier depends on several premises, i.e. "idle resources", the degree of import leakage and the marginal propensity to consume. With large numbers of unemployed, but employable, workers and a large domestic economy (small import leakage), the first two factors indicate that there has been a sizeable fiscal multiplier in the US over the last five to six years. However, if increased income ends up as private saving because the marginal propensity to consume is close to zero, the fiscal policy multiplier may nevertheless be very small.

The paper proceeds as follows. In the next section, we outline the implied (and testable) VAR parameter restrictions of the PIH, and we discuss how we will proceed to explore the empirical relevance of these theoretical conjectures. In Section 3 , we present 
the data sets that are used in the econometric analyses. Results from the MSA specific analyses over the Great Moderation are discussed in Section 4 . In the same section, we explore how our main conclusions are affected by extending the data set to include the financial crisis period. In Section 5, we analyze whether the evidence at the aggregate level is congruent with the MSA evidence. The analysis in that section comes in the form of a small identified structural econometric model of the income-consumption VAR. The final section concludes the paper.

\section{The 'saving for a rainy day' hypothesis}

As shown by Campbell (1987), for an infinitely lived consumer and no credit constraints, saving is given by the discounted sum of anticipated declines in income:

$$
S_{t}=-\sum_{i=1}^{\infty}\left(\frac{1}{1+r}\right)^{i} E_{t} \Delta Y_{t+i}
$$

where $S_{t}$ denotes saving in period $t, r$ is the subjective discount rate, and $E_{t} Y_{t+i}$ is the conditional expectation of period $t+i$ income, given information available in period $t .^{3}$ The interpretation is that consumers wish to avoid the utility loss of reductions in consumption, so they smooth consumption intertemporally, they 'save for a rainy day'.

Define $\Delta Y_{t+i}=E_{t} \Delta Y_{t+i}+v_{t+i},(i>1)$ where the forecast errors, $v_{t+i}$, have zero means and constant variances. Substitution in (1) gives:

$$
S_{t}=-\sum_{i=1}^{\infty}\left(\frac{1}{1+r}\right)^{i} \Delta Y_{t+i}+\sum_{i=1}^{\infty}\left(\frac{1}{1+r}\right)^{i} v_{t+i}
$$

showing that $S_{t}$ is the sum of a linear filter of leads in stationary income changes, and another linear filter of forecast errors, which are $I(0)$ by assumption. Thus, it follows logically that $S_{t}$ is stationary, $I(0)$. As noted by Muellbauer and Lattimore (1995), stationarity of $S_{t}$ does not require that income follows a pure random-walk - it holds also

\footnotetext{
${ }^{3}$ In addition to the mentioned assumptions, Campbell's derivation assumed quadratic utility function and rational expectations about future income.
} 
in the case where income follows an ARIMA process.

Campbell further noted the implication that, under the null of the PIH, saving should encapsulate the superior information of the agent to the econometrician, meaning that lagged saving should Granger-cause income in the bivariate VAR. This is also logical, since Hall's Euler-equation implies that consumption follows a first order Markov process. Hence, consumption should not be Granger-caused by lagged income, or lagged saving, in the VAR.

\subsection{An econometric framework for testing the 'saving for a rainy day' hypothesis}

In the following, we measure consumption and income in natural logarithms, where $c_{t}$ denotes consumption in period $t$ and $y_{t}$ is income in period $t$. We assume that both consumption and income are integrated of order one, $I(1)$. Due to the non-stationarity of the two series, cointegration represents a common ground between the consumption function approach, which assumes a causal link from income to consumption (see e.g. Davidson et al. (1978)), and the permanent-income/life-cycle theories, which imply the consumption Euler equation - a cornerstone in conventional macroeconomic models, cf. Ljungqvist and Sargent (2004) $!^{4}$

Although our econometric analysis makes use of models with longer lags and possible structural breaks, the main hypotheses about saving behavior can be formulated with reference to a first order bivariate VAR with constant parameters:

$$
\begin{aligned}
& c_{t}=\kappa+\phi_{c c} c_{t-1}+\phi_{c y} y_{t-1}+\varepsilon_{c, t} \\
& y_{t}=\varphi+\phi_{y c} c_{t-1}+\phi_{y y} y_{t-1}+\varepsilon_{y, t}
\end{aligned}
$$

where the disturbances, $\varepsilon_{c, t}$, and $\varepsilon_{y, t}$ have a joint normal distribution. Their variances

\footnotetext{
4 "All of macroeconomics too seems to have descended from a common source, Irvin Fisher's and Milton Friedman's consumption Euler equation, the cornerstone of the permanent income theory of consumption", Ljungqvist and Sargent (2004, p.3).
} 
are $\sigma_{c}^{2}$ and $\sigma_{y}^{2}$, respectively, and the correlation coefficient is denoted $\rho_{c, y}$.

Cointegration implies that the matrix of autoregressive coefficients $\boldsymbol{\Phi}=\left(\begin{array}{cc}\phi_{c c} & \phi_{c y} \\ \phi_{y c} & \phi_{y y}\end{array}\right)$ has one unit root, and one stable root. The equilibrium correction (EqCM) representation of (3) and (4) is therefore:

$$
\begin{array}{ll}
\Delta c_{t}=\kappa+\alpha_{c}\left[c_{t-1}-\beta_{y} y_{t-1}\right]+\varepsilon_{c, t} & 0 \leq-\alpha_{c}<1, \\
\Delta y_{t}=\varphi+\alpha_{y}\left[c_{t-1}-\beta_{y} y_{t-1}\right]+\varepsilon_{y, t} & 0 \leq \alpha_{y}<1,
\end{array}
$$

where $\beta_{y}$ is the cointegration coefficient, while $\alpha_{c}$ and $\alpha_{y}$ are the adjustment coefficients, where we have normalized on consumption in the long-run cointegrating relationship, $\left(c_{t-1}-\beta_{y} y_{t-1}\right)$.

It is useful to reparameterize the system with mean-zero equilibrium correction terms. To achieve that, define $\eta_{c}=\mathrm{E}\left[\Delta c_{t}\right], \eta_{y}=\mathrm{E}\left[\Delta y_{t}\right]$ and $\mu=\mathrm{E}\left[c_{t}-\beta_{y} y_{t}\right]$. Thus, the constant terms in (5) and (6) can be expressed as $\kappa=\eta_{c}+\alpha_{c} \mu$ and $\varphi=\eta_{y}-\alpha_{y} \mu$, respectively. We then have:

$$
\begin{array}{ll}
\Delta c_{t}=\eta_{c}+\alpha_{c}\left[c_{t-1}-\beta_{y} y_{t-1}-\mu\right]+\varepsilon_{c, t} & 0 \leq-\alpha_{c}<1, \\
\Delta y_{t}=\eta_{y}+\alpha_{y}\left[c_{t-1}-\beta_{y} y_{t-1}-\mu\right]+\varepsilon_{y, t} & 0 \leq \alpha_{y}<1 .
\end{array}
$$

In the case of $\beta_{y}=1$, the savings rate, $(y-c)$, is $\mathrm{I}(0)$ and $\mu$ is its long-run mean.

\subsection{Consumption function model of the VAR}

Underlying the consumption function approach is the idea that consumption is equilibrium correcting, i.e., $0<-\alpha_{c}<1$. Given that this requirement is fulfilled, there are two possibilities for the coefficient $\alpha_{y}$ : (i) $0<\alpha_{y}<1$ or (ii) $\alpha_{y}=0$. The first case is 
consistent with hours worked etc. being demand determined and that $y_{t}$ adjusts to past disequilibria. In econometric terms, there is mutual (Granger) causation between income and consumption, see Engle et al. (1983). The second possibility implies that income is supply determined. In the context of the VAR, the restriction that $\alpha_{y}=0$ implies that income is weakly exogenous with respect to the long-run income elasticity, $\beta_{y}$, see e.g. Johansen (1992). Moreover, with the dynamics restricted to the first order case, there is one-way Granger causation from income to consumption, so income is also strongly exogenous.

Interpretation is aided by writing the system (7)-(8) in model form:

$$
\begin{aligned}
\Delta c_{t} & =\eta_{c}+\gamma_{c}+\pi_{c} \Delta y_{t}+\alpha_{c}^{\prime}\left[c_{t-1}-\beta_{y} y_{t-1}-\mu\right]+\varepsilon_{c, t}^{\prime} \\
\Delta y_{t} & =\eta_{y}+\alpha_{y}\left[c_{t-1}-\beta_{y} y_{t-1}-\mu\right]+\varepsilon_{y, t}
\end{aligned}
$$

where (9) is a conditional consumption function, while (10) is a marginal income equation. From the properties of the bivariate normal distribution, we have:

$$
\begin{aligned}
\alpha_{c}^{\prime} & =\alpha_{c}-\pi_{c} \alpha_{y} \\
\pi_{c} & =\rho_{c, y} \frac{\sigma_{c}}{\sigma_{y}} \\
\gamma_{c} & =-\eta_{y} \pi_{c}, \\
\varepsilon_{c, t}^{\prime} & =\varepsilon_{c, t}-\pi_{c} \varepsilon_{y, t} .
\end{aligned}
$$

Note that along a growth path characterized by $\mathrm{E}\left[c_{t-1}-\beta_{y} y_{t-1}-\mu\right]=0$, the growth rates of $c_{t}$ and $y_{t}$ are proportional:

$$
\eta_{c}=\beta_{y} \eta_{y}
$$

As noted, the system represented by (9)-(10) is merely a reparameterization of the VAR by means of "conditional plus marginal" model equations. When the (testable) restriction that $\alpha_{y}=0$ holds, (9)-(10) may be expressed as: 


$$
\begin{aligned}
\Delta c_{t} & =\eta_{c}+\gamma_{c}+\pi_{c} \Delta y_{t}+\alpha_{c}\left[c_{t-1}-\beta_{y} y_{t-1}-\mu\right]+\varepsilon_{c, t}^{\prime} \\
\Delta y_{t} & =\eta_{y}+\varepsilon_{y, t}
\end{aligned}
$$

with $\eta_{y}=\varphi$, since there is no equilibrium correction in income.

Equations (9) and (13) are conditional equilibrium correction equations for $c_{t}$, see e.g., Hendry (1995, Chapter 7), Davidson et al. (1978) and Hendry and von Ungern-Sternberg (1981). However, (9) is more general, since (13) rests on the assumption that causation runs from income to consumption, and not the other way around.

\subsection{Euler equation model of the VAR}

According to the permanent income/life cycle hypothesis, the evolution of consumption is shaped by tastes and life cycle needs. The stochastic permanent income/life cycle hypothesis holds that consumption growth, $\Delta c_{t}$, is not Granger-caused by the lagged income level, hence $\alpha_{c}=0$ in (7). Thus, it is assumed that consumption growth is orthogonal to $\left(c_{t-1}-\beta_{y} y_{t-1}-\mu\right)$, the linear and stationary combination of consumption and income, i.e. the cointegrating relationship.

As in the former case, we may rewrite the system (7)-(8) in model form (conditional on $\left.\alpha_{c}=0\right)$ :

$$
\begin{aligned}
\Delta c_{t} & =\eta_{c}+\varepsilon_{c, t} \\
\Delta y_{t} & =\eta_{y}+\gamma_{y}+\pi_{y} \Delta c_{t}+\alpha_{y}\left[c_{t-1}-\beta_{y} y_{t-1}-\mu\right]+\varepsilon_{y, t}^{\prime}
\end{aligned}
$$

where (15) is a marginal model for consumption, while 16 is a conditional model for 
income. Again, from the properties of the bivariate normal distribution, we have:

$$
\begin{aligned}
\pi_{y} & =\rho_{c, y} \frac{\sigma_{y}}{\sigma_{c}} \\
\gamma_{y} & =-\eta_{y} \pi_{y} \\
\varepsilon_{y, t}^{\prime} & =\varepsilon_{y, t}-\pi_{y} \varepsilon_{c, t}
\end{aligned}
$$

Given $\alpha_{c}=0$, cointegration implies that $0<\alpha_{y}<1$, since - as we know from the Engle-Granger representation theorem (Engle and Granger, 1987) - cointegration implies equilibrium correction, and vice versa. The interpretation for the case of $\beta_{y}=1$, due to Campbell (1987), is that growth in disposable income is negatively related to the lagged savings rate because consumers have superior information about their income prospects. If saving increases "today", this is because consumers expect income to decline in the future. Hence, after first observing a rise in the savings rate, we will observe a fall in income in subsequent periods, since households are 'saving for a rainy day'.

Furthermore, although income is not Granger-causing consumption in (15), this does not preclude contemporaneous correlation, since we can have $\pi_{y} \neq 0$ without violating the Euler-equation restriction (i.e., $\alpha_{c}=0$ and $\left.\Delta c_{t} \perp\left(c_{t-1}-\beta_{y} y_{t-1}-\mu\right)\right)$.

The theoretical prediction that income is equilibrium correcting carries over to less stylized situations: first, if a proportion of the consumers are subject to liquidity or borrowing constraints, we may find that aggregate income is Granger-causing aggregate consumption, as in Campbell and Mankiw (1989). Still, as long as the remaining proportion of consumers adjust their consumption to expected permanent income, observed aggregate disposable income is negatively related to the aggregate savings rate, so we would still find $\alpha_{y}>0$. Second, the orthogonality condition may not hold if the measure of consumption expenditure includes purchases of durables, see e.g. Deaton (1992, p.99103), but the implication that $\alpha_{y}>0$ still holds. Finally, the basic implication of $\alpha_{y}>0$ is unaffected by modifications of the basic Euler equation, e.g., non-constant expected future interest rates (Haug, 1996) and inclusion of demographic variables. 


\subsection{Generalizations to higher order VARs and allowing for re- gional heterogeneity}

To test for the absence of cointegration between consumption and income, and to explore the direction of equilibrium correction and Granger causality, we develop both MSAspecific econometric models and a model on aggregate data.

Our main reference is a $\operatorname{VAR}\left(p_{j}\right)$ model of the following form:

$$
\boldsymbol{y}_{j, t}=\sum_{s=1}^{p_{j}} \boldsymbol{A}_{j, s} \boldsymbol{y}_{j, t-s}+\boldsymbol{\Phi}_{j} \boldsymbol{D}_{j, t}+\boldsymbol{\varepsilon}_{j, t}
$$

where the index $j$ represents MSA unit. The vector $\boldsymbol{y}_{j, t}$ comprises real consumption and real disposable income. Deterministic terms (linear trend and a constant) are collected in the vector $\boldsymbol{D}_{j, t}$. House price changes and the real interest rate are also collected in $\boldsymbol{D}_{j, t}$. The disturbances are assumed to follow a multivariate normal distribution, with expectation $\mathbf{0}_{2 \times 1}$ and covariance matrix $\boldsymbol{\Sigma}_{j}$, i.e. $\boldsymbol{\varepsilon}_{j, t} \sim M V N\left(\mathbf{0}_{2 \times 1}, \boldsymbol{\Sigma}_{j}\right)$.

A model using aggregate data is a special case of the above model, since by imposing $\boldsymbol{A}_{j, s}=\boldsymbol{A}_{s}, \boldsymbol{\Phi}_{j}=\boldsymbol{\Phi} \forall j, s$, while also taking sums over all $j \in M \supset N$, where $M$ covers all MSAs in the US, we have a standard VAR for aggregate data. Since the aggregate model is a restricted version of the MSA-specific models, we shall concentrate our explanation of the econometric approach we pursue on the MSA-specific models.

For all areas, we start with a lag length of 5 , i.e. $p_{j}=5$. Then, we select the lag length (between 1 and 5) that minimizes the Akaike Information Criterium (AIC). Conditional on the optimal lag truncation, $p_{j}^{*}$, we consider 18 on vector equilibrium correction (VECM) form. We follow the recommendation of Harbo et al. (1998) for partial systems and restrict a deterministic trend to enter the cointegration space. Letting $\tilde{\boldsymbol{y}}_{j, t}=\left(\boldsymbol{y}_{j, t}^{\prime}, \text { trend }_{j}\right)^{\prime}$, the VECM representation of the VAR model takes the following 


$$
\Delta \boldsymbol{y}_{j, t}=\boldsymbol{\Pi}_{j} \tilde{\boldsymbol{y}}_{j, t-1}+\sum_{s=1}^{p_{j}^{*}-1} \boldsymbol{\Gamma}_{j, s} \Delta \boldsymbol{y}_{j, t-s}+\tilde{\boldsymbol{\Phi}}_{j} \tilde{\boldsymbol{D}}_{j, t}+\boldsymbol{\varepsilon}_{j, t}
$$

where $\tilde{\boldsymbol{D}}_{j, t}$ contains the constant term, the real interest rate and house price changes. All coefficient matrices are redefined conformably.

To determine the rank of the matrix $\boldsymbol{\Pi}_{j}$, we use the trace test of Johansen (1988). The rank of $\boldsymbol{\Pi}_{j}$ corresponds to the number of independent linear combinations between the variables in $\tilde{\boldsymbol{y}}_{j, t}$ that are stationary, i.e. the number of cointegrating relationships. When $\boldsymbol{\Pi}_{j}$ has reduced rank, we can write $\boldsymbol{\Pi}_{j}=\boldsymbol{\alpha}_{j} \boldsymbol{\beta}_{j}^{\prime}$, where $\boldsymbol{\beta}_{j}$ is a $\left(l_{j}+1\right) \times r_{j}$ matrix and $\boldsymbol{\alpha}_{j}$ is a $l_{j} \times r_{j}$ matrix corresponding to the long-run coefficients and loading factors (adjustment coefficients), respectively. The rank of $\boldsymbol{\Pi}_{j}$ is denoted by $r_{j}$, while $l_{j}+1$ refers to the number of endogenous variables (plus the deterministic trend, which is restricted to lie in the space spanned by $\boldsymbol{\alpha}_{j}$ ). In all areas, $l_{j}$ is equal to 2 (real consumption and real disposable income).

Conditional on a non-zero rank, we can estimate the parameters in the cointegration space. In particular, our approach allows us to explore heterogeneities in both long-run income elasticities and the speed of adjustment parameters. Moreover, cointegration implies that there is Granger causality in at least one direction (Granger, 1986). To formally explore the direction of causality, in the Granger sense, consider the reduced rank representation of the VECM in (19):

$$
\begin{aligned}
\left(\begin{array}{c}
\Delta c_{j, t} \\
\Delta y_{j, t}
\end{array}\right) & =\left(\begin{array}{c}
\alpha_{c_{j}} \\
\alpha_{y_{j}}
\end{array}\right)\left(c_{j, t-1}-\beta_{y, j} y_{j, t-1}-\beta_{t r e n d, j} \text { trend }_{t-1}\right) \\
& +\sum_{s=1}^{p_{j}^{*}-1}\left(\begin{array}{cc}
\Gamma_{11, j, s} & \Gamma_{12, j, s} \\
\Gamma_{21, j, s} & \Gamma_{22, j, s}
\end{array}\right)\left(\begin{array}{c}
\Delta c_{j, t-s} \\
\Delta y_{j, t-s}
\end{array}\right)+\tilde{\boldsymbol{\Phi}}_{j} \tilde{\boldsymbol{D}}_{j, t}+\boldsymbol{\varepsilon}_{j, t}
\end{aligned}
$$

5 Johansen $(1994,1995)$ and Harbo et al. 1998$).$ 
where we have normalized the first coefficient in the cointegration space with respect to consumption. A test for GNC from income to consumption in area $j$ amounts to testing the joint hypothesis that $\alpha_{c_{j}}=\Gamma_{12, j, s}=0 \forall s$, while a test for GNC from consumption to income in area $j$ is a test of the joint hypothesis that $\alpha_{y_{j}}=\Gamma_{21, j, s}=0 \forall s$. In our empirical analysis, we shall consider these tests for each of the 100 MSAs covered by our sample.

\subsection{Allowing for MSA-specific structural breaks}

When building the MSA-specific econometric models, we make use of the impulse indicator saturation (IIS) algorithm, which is an integrated part of the Autometrics algorithm implemented within OxMetrics (see Doornik (2009) and Hendry and Doornik (2009)) to allow for MSA-specific structural breaks.

The IIS algorithm includes an impulse dummy for each observation in the information set. More precisely, this implies that the baseline VAR in (18) can be modified to:

$$
\boldsymbol{y}_{j, t}=\sum_{s=1}^{p_{j}} \boldsymbol{A}_{j, s} \boldsymbol{y}_{j, t-s}+\boldsymbol{\Phi}_{j} \boldsymbol{D}_{j, t}+\boldsymbol{\Psi}_{j} \boldsymbol{I}_{t}+\boldsymbol{\varepsilon}_{j, t} t=t_{j}, \ldots, T
$$

where $\boldsymbol{I}_{t}$ is a $\left(T+1-t_{j}\right) \times\left(T+1-t_{j}\right)$ matrix of impulse dummies. Since this entails that there are more variables than observations, the model is estimated in blocks to determine which indicators are significant (see Hendry et al. (2008) and Johansen and Nielsen $(2009))$. If we let the retained indicators for area $j$ be collected in the $(T+1-$ $\left.t_{j}\right) \times Q_{j}$ matrix $\tilde{\boldsymbol{I}}_{j, t}$, with $Q_{j}<\left(T+1-t_{j}\right)$, the IIS robust reparameterization of the VAR takes the following form:

$$
\Delta \boldsymbol{y}_{j, t}=\boldsymbol{\Pi}_{j} \tilde{\boldsymbol{y}}_{j, t-1}+\sum_{s=1}^{p_{j}^{*}-1} \boldsymbol{\Gamma}_{j, s} \Delta \boldsymbol{y}_{j, t-s}+\tilde{\boldsymbol{\Phi}}_{j} \tilde{\boldsymbol{D}}_{j, t}+\tilde{\boldsymbol{\Psi}}_{j} \tilde{\boldsymbol{I}}_{j, t}+\boldsymbol{\varepsilon}_{j, t}
$$


After having estimated (21) employing Autometrics, we follow the same steps as those described in the previous section, i.e. we test down the lag length using the AIC, determine the rank of the matrix $\boldsymbol{\Pi}_{j}$, and conduct tests for both weak exogeneity and Granger non-causality. Thus, the estimates and tests obtained in this case can be seen as being robustified to MSA-specific structural breaks (Johansen and Nielsen, 2009).

Applying the IIS algorithm, an average of $\alpha^{I I S} \times\left(T+1-t_{j}\right)$ indicators will be retained by chance, where $\alpha^{I I S}$ denotes a pre-specified significance level used for the selection of indicators. This is indeed a low cost to pay for robustifying a model to intermittent structural breaks and past data contamination that can cause an otherwise sensible econometric model to break down. Castle et al. (2012) show that the IIS algorithm is successful in detecting multiple breaks in the data.

When applying the IIS algorithm to the VAR model of area $j$, the significance level, $\alpha^{I I S}$, is set to $0.1 \%$. With this significance level, the chance of retaining irrelevant indicator variables is relatively low, and as the MSA results below demonstrate, very few indicators are picked up on average. The same is true for the macro time series analysis.

\section{Data}

We have collected quarterly time series data at both the national level and for the 100 largest MSAs in the US. For most of the areas, the data set spans the period 1980q1$2011 \mathrm{q} 4(T=124)$.

The MSAs included in our MSA data set cover all but four of the 50 US states and are spread out in different geographical regions. To ease the exposition, we shall follow the Census Bureau and divide the US into four major regions (West, Midwest, South and East) when discussing some of our results.6 The geographical divide of the four regions is presented in Figure 1.

With reference to Figure 1, 25 of the MSAs included in our sample belong to the

\footnotetext{
${ }^{6}$ The estimation and testing are, however, carried out for each MSA.
} 


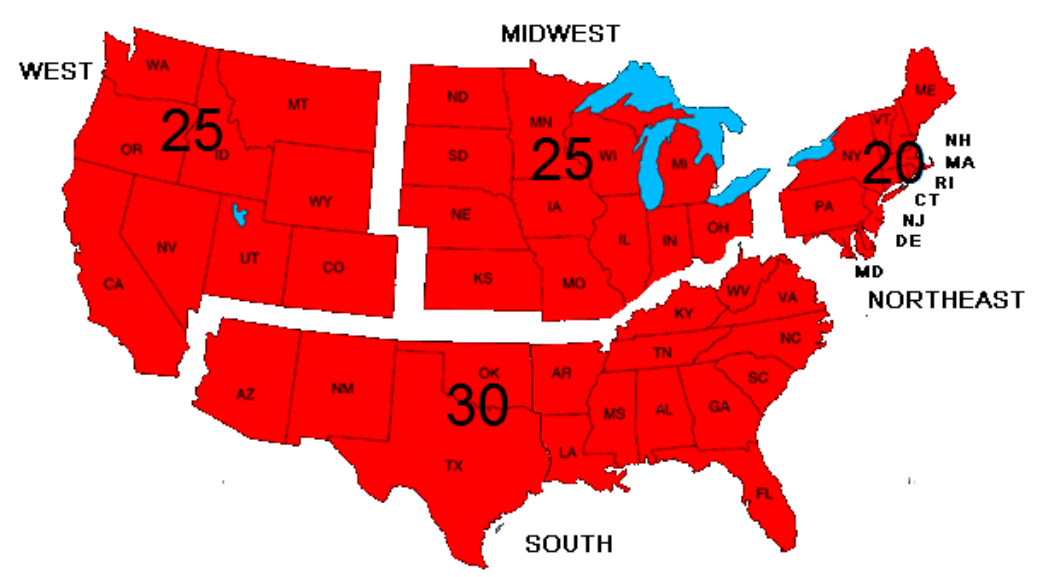

Figure 1: Main geographical regions in the US

West, 20 to the East, 30 to the South and 25 to the Midwest.

The income data, $y_{j, t}$, measure personal disposable income in billions of USD. Unfortunately, disaggregate consumption data are not available at the MSA level (in fact it is not even available at the state level). For that reason, we use data on retail sales in billions of USD as a proxy for consumption, $c_{j, t}$, which is a drawback of our analysis. That said, as pointed out by Sorensen and Luengo-Prado (2008), the correlation between aggregate US retail sales and non-durable consumption is very high. Thus, in the absence of data on MSA level consumption, we take this to be a relatively good proxy. Similar data have been used in e.g. Case et al. (2012), Sorensen and Luengo-Prado (2008) and Dejuan et al. (2004), who all consider state level consumption in the US. We follow Case et al. (2012) and use the retail sales data supplied by Moody's (formerly supplied by Regional Financial Associates). House price data are collected from the FHFA, and all series are deflated by the corresponding MSA level CPI measure, which has also been collected from Moody's. Finally, MSA-specific real interest rates are constructed by subtracting the MSA level CPI inflation from the nominal 3-month T-bill. In the empirical analysis, all variables, except the real interest rate, are included in log form.

All data series used for the aggregate macro time series are taken from the FRED data base of the St. Louis Fed. The income data measure private disposable income, while the consumption data are personal consumption expenditures. House prices are measured 
by the FHFA house price index. All variables are considered in real terms, and the nominal-to-real transformations are achieved by deflating by the CPI. The real interest rate is the nominal 3-month T-bill less CPI inflation. We have also collected aggregate retails sales data (similar to those used for the MSA level analysis) to explore how this alternative operationalization affects the aggregate results. While a similar robustness cannot be done with respect to the MSA analysis due to data availability, we take it as reassuring that the qualitative results from the aggregate analysis are relatively invariant to the operationalization of the consumption variable.

The discussion in Section 2 is based on the premise that the time series for income and consumption contain unit roots. To investigate the empirical relevance of this assumption, we have tested the order of integration of the data series using standard ADF tests (Dickey and Fuller, 1979) for each of the areas. In particular, we started with a lag length of 5, including a deterministic trend in the ADF regressions. Then, the optimal lag truncation was chosen by a sequence of t-tests. The average order of integration is close to one for both series $]^{7}$ Based on these results, we feel confident in continuing our analysis under the modeling assumption that both series are integrated of order one.

\section{MSA-based evidence about rainy day behavior}

\subsection{Cointegration results for the MSA data set}

In this section, we present the results from the MSA-specific econometric analysis using data for the Great Moderation (1980q1-2007q4). In the first step of our estimation approach, the IIS algorithm picks up a little less than 1 dummy on average (confer the last row in the first column of Table 1). Based on AIC, we find the average optimal lag truncation to be just below 4, and the hypothesis of co-trending is supported for a majority of the areas $(72 \%)$ when we use a $1 \%$ significance level. While detailed results for the individual MSAs are presented in Table A.1 A.4 in Appendix A. Table 1 reports

\footnotetext{
${ }^{7}$ Detailed results from the unit root tests at the MSA level are available upon request.
} 
Table 1: Averages and percentages of some key model features for Great Moderation sample (1980q1-2007q4), ordered by census region

\begin{tabular}{l|ccccccc}
\hline Region & Dummies (avg.) & $p^{*}$ (avg.) & Rank( $\mathbf{\Pi})$ (avg.) & Auto. (\%) & Norm. (\%) & Hetero. (\%) & $\beta_{\text {trend }}=0(\%)$ \\
\hline West & 1.20 & 3.48 & 0.60 & 92.00 & 96.00 & 92.00 & 84.00 \\
East & 0.95 & 3.85 & 1.20 & 95.00 & 95.00 & 95.00 & 85.00 \\
South & 0.44 & 3.92 & 0.96 & 100.00 & 96.00 & 100.00 & 44.00 \\
Midwest & 1.13 & 4.20 & 0.90 & 90.00 & 100.00 & 90.00 & 76.67 \\
\hline All & 0.94 & 3.88 & 0.90 & 94.00 & 97.00 & 94.00 & 72.00 \\
\hline
\end{tabular}

Notes: Columns 2-4 report the average number of dummies, Dummies (avg.), included in the econometric models within each of the four major regions, as well as the average optimal lag truncation, $p^{*}$ (avg.) and average number of cointegrating relationships, $\operatorname{Rank}(\boldsymbol{\Pi})$. Columns 5-7 report the percentage number of times where we cannot reject absence of autocorrelation, non-normality and heteroskedasticity. The final column displays the percentage number of areas where we find support for co-trending, i.e. $\beta_{\text {trend }}=0$. The final row in each column reports the same figures for all the MSAs covered by the sample (all areas). Detailed results for the individual MSAs are reported in Table A.1 A.4 in Appendix A.

a summary of the average results across each of the four census regions illustrated in Figure 1.

As is evident from Table 1, we find overwhelming evidence in a majority of the areas that the residuals are well behaved, i.e. there are no sings of autocorrelation, heteroskedasticity nor departures from normality. It is also evident that the average rank is just around one, which is also what we will impose for the rest of the analysis. Imposing the reduced rank restriction and normalizing the cointegrating vector with respect to consumption $\left(\beta_{c, j}=1 \forall j\right)$, we obtain estimates of the long-run income elasticity. While detailed results for the individual MSAs are reported in Table A.5 A.8, Figure 2 plots the point estimates for the long-run income elasticity for all of the areas included in our sample - in descending order.

For all except five areas $\sqrt[8]{8}$ the estimated long-run income elasticity is positive, as would be expected. The average long-run income elasticity across all areas is found to be 0.86 , and the standard error of this mean group estimate is 0.03 , see the second and fourth column in Table 2 [9

To have a first look at the empirical relevance of the weak implication of the PIH (implying that $\alpha_{c, j}=0$ and $\alpha_{y, j}>0$ ), Figure 3 plots the distribution of the two adjustment parameters across the 100 MSAs 10

\footnotetext{
${ }^{8}$ These areas are Miami-Miami Beach-Kendall (FL), Lansing-East Lansing (MI), Detroit-LivoniaDearborn (MI), Sioux Falls (SD) and Ann Arbor (MI).

${ }^{9}$ In calculating the mean group estimates, we have excluded the five areas where estimated income elasticity was negative.

${ }^{10}$ Again, detailed results for each MSA can be found in Table A.5 A.8 in Appendix A.
} 
It is clear that in a majority of the areas, we find that $\alpha_{c, j}<0$, which is consistent with a consumption function approach. The average estimated speed of adjustment in the consumption equation is found to be -0.12 , see Column 5 in Table 2 . Looking at the adjustment coefficient associated with the income equation, there are several cases where it is found to be negative, while in a majority of the cases it is found to be positive. The average estimate, around 0.03 , is substantially lower (in absolute value) than the adjustment parameter in the consumption equation. Hence, results thus far suggest mixed support for the 'saving for a rainy day' hypothesis as an empirically relevant description of US consumption behavior. In the next section, we shall explore the direction of causality in more detail by conducting formal tests for both weak exogeneity and Granger noncausality for each of the MSAs in the sample. 


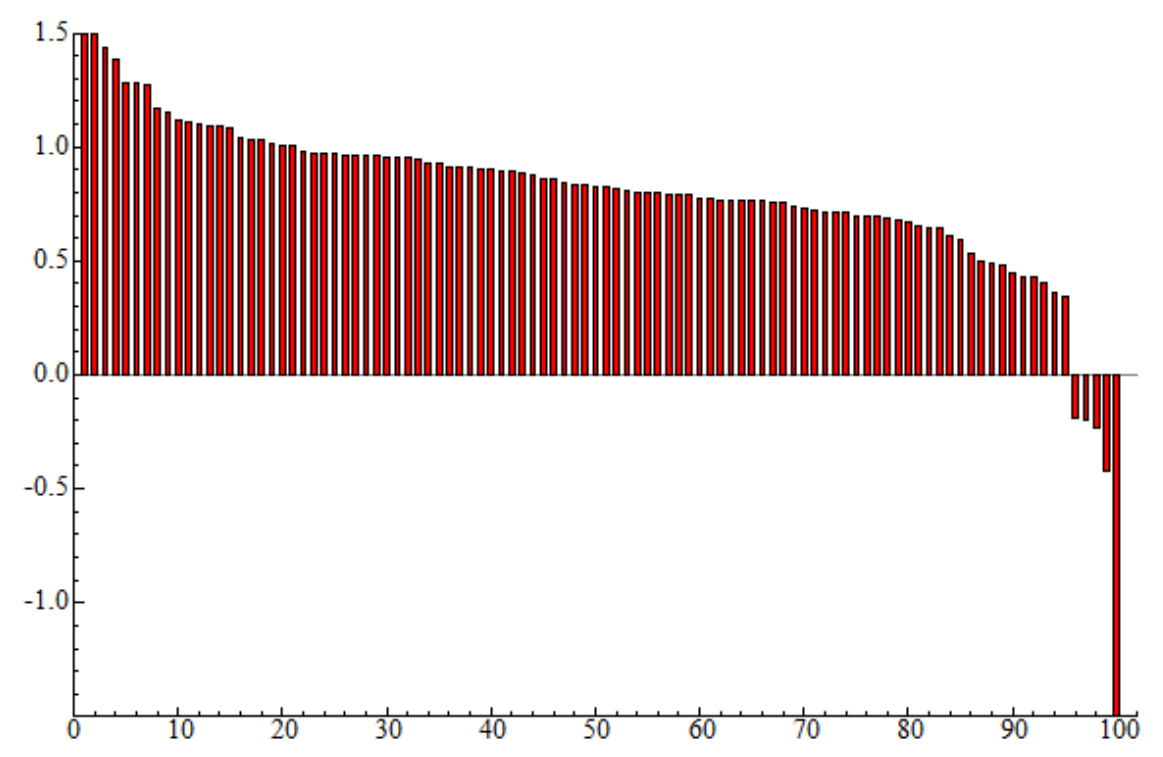

Figure 2: Estimated long-run income elasticities $\left(\beta_{y, j}\right)$ for all MSAs for Great Moderation sample (1980q1-2007q4), in descending order

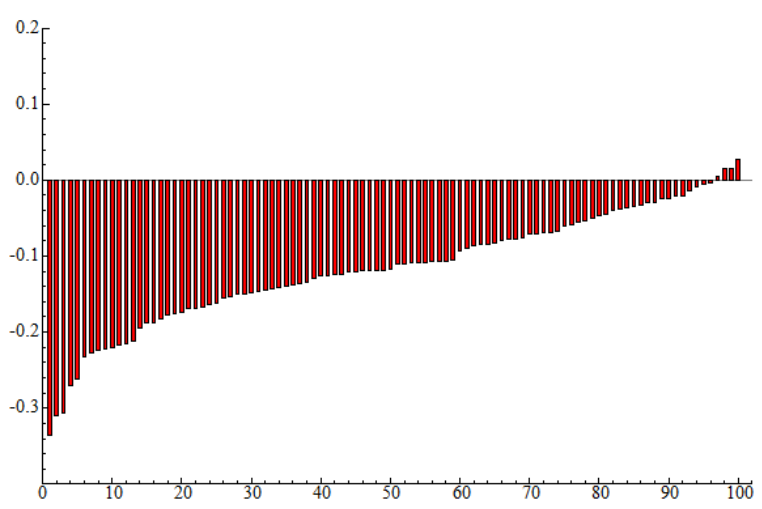

(a) $\alpha_{c, j}$

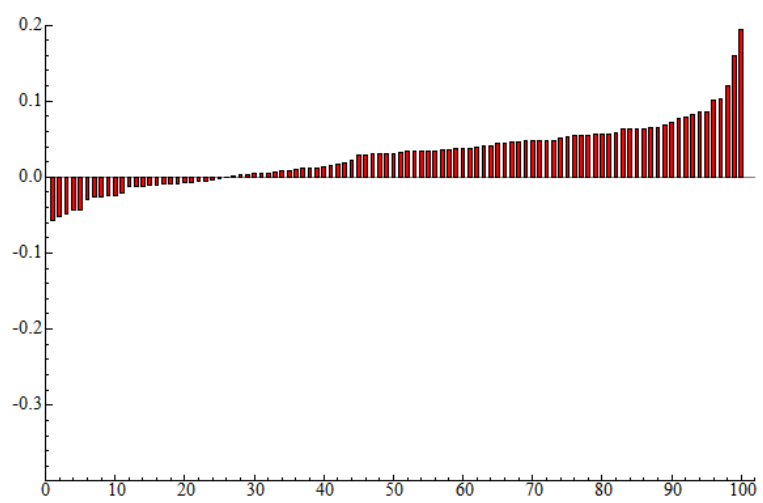

(b) $\alpha_{y, j}$

Figure 3: Adjustment parameter in consumption equation $\left(\alpha_{c, j}\right)$ and in income equation $\left(\alpha_{y, j}\right)$ for Great Moderation sample (1980q1-2007q4), in descending order 


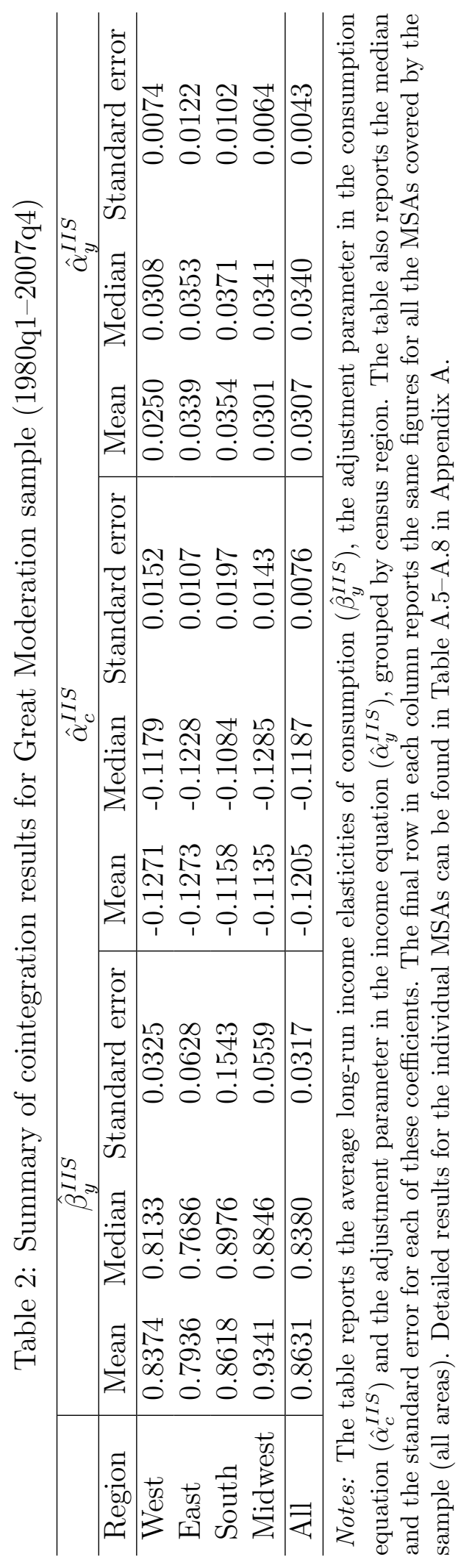




\subsection{Weak exogeneity and Granger non-causality}

Using the optimal lag truncations of the VAR models, as found in the previous section, together with the estimated cointegrating vectors, we derive the vector equilibrium correction representation of the CVAR models (confer (20)). The VECM for each area is estimated by FIML, and Table 3 summarizes the main results regarding tests for both weak exogeneity and Granger non-causality. ${ }^{11}$

As is evident by inspecting the second and third column, weak exogeneity of consumption with respect to the cointegrating vector is rejected in a majority of the cases (87\%), while weak exogeneity of income is rejected only for $38 \%$ of the MSAs. This is at odds with the weak implication of the PIH, and further support for this claim is provided by the results in Column 4 and Column 5, where we report the percentage number of times where we find evidence that income is Granger-causing consumption (84\%) and the percentage number of times where we find evidence that consumption is Granger-causing income $(69 \%)$. It is also interesting to look at the Granger causality tests for house prices. In about $55 \%$ of the areas, we find that house prices Granger-cause consumption, suggesting that house prices may be important for consumption dynamics in some MSAs. The same figure for income is around $32 \%$.

\subsection{Including the financial crisis period}

We have seen that the 'saving for a rainy day' hypothesis receives mixed support over the Great Moderation period. The empirical evidence is clearly supportive to the interpretation that consumption represents the main equilibrium correction mechanism.

In this section, we briefly check if the assessment changes when we extend the sample to include the financial crisis period and the ensuing income and job crisis, i.e. the sample now covers the period from 1980q1 to 2011q4. The distribution of long-run

\footnotetext{
${ }^{11}$ Note that the reported results are based on the MSAs where the estimated long-run income elasticity was "meaningful"- defined as $0<\hat{\beta}_{y_{j}}<2$. The only cases where this restriction is violated is for the five areas where a negative long-run income elasticity was found. Thus, the tests for weak ecogeneity and GNC are conducted for the remaining 95 MSAs.
} 
Table 3: Tests for weak exogeneity and Granger non-causality for Great Moderation sample (1980q1-2007q4)

\begin{tabular}{l|cc|cc|cc}
\hline Region & $\alpha_{c} \neq 0$ & $\alpha_{y} \neq 0$ & $y \underset{G C}{\rightarrow} c$ & $c \underset{G C}{\rightarrow} y$ & $p h \underset{G C}{\rightarrow} c$ & $p h \underset{G C}{\rightarrow} y$ \\
\hline West & 92.00 & 28.00 & 88.00 & 80.00 & 36.00 & 28.00 \\
East & 100.00 & 45.00 & 90.00 & 60.00 & 70.00 & 20.00 \\
South & 90.48 & 33.33 & 76.19 & 47.62 & 52.38 & 33.33 \\
Midwest & 72.41 & 44.83 & 82.76 & 82.76 & 62.07 & 41.38 \\
\hline All & 87.37 & 37.89 & 84.21 & 69.47 & 54.74 & 31.58 \\
\hline
\end{tabular}

Notes: Column 2-4 report the percentage number of times where weak exogeneity of consumption is rejected $\left(\alpha_{c} \neq 0\right)$ and the percentage number of times where weak exogeneity of income $\left(\alpha_{y} \neq 0\right)$ is rejected, as well as the percentage number of times where we find that income Granger-causes consumption $(y \overrightarrow{G C} c)$ and vice versa $(c \underset{G C}{\rightarrow} y)$. The final two columns report the percentage number of times where we find that house prices Granger-cause consumption $(p h \underset{G C}{\rightarrow} c)$ and income $(p h \underset{G C}{\rightarrow} y)$.

income elasticities is plotted in Figure 4. It is clear that the result of a positive income elasticity in a majority of the areas is retained. In fact, estimated income elasticity now turns negative only for two areas ${ }^{12}$

In Figure 5, we plot the estimated long-run elasticities from the Great Moderation sample against the estimated long-run elasticities obtained on the full sample. It is clear that the coefficients are very stable, which is a reassuring finding.

The estimated adjustment parameters in the consumption and income equation from the full sample analysis are illustrated in Figure 6. It is evident that the adjustment parameter in the consumption function is negative in most areas and, if anything, a bit more negative than in the Great Moderation sample. The distribution of the adjustment parameter in the income equation is also similar to the Great Moderation sample.

Based on the above results, it is clear that the inclusion of the financial crisis period in the estimation sample does not alter our main conclusions. If anything, our results are strengthened when the sample is extended. This is also seen from the mean and median estimates for long-run income elasticity and the adjustment parameters, which are summarized in Table 4$]^{13}$ Comparing these results to the results obtained on the

\footnotetext{
${ }^{12}$ These areas are Detroit-Livonia-Dearborn (MI) and Lansing-East Lansing (MI), where negative income elasticities were also found on the Great Moderation sample.

${ }^{13}$ Detailed results for the individual MSAs from the full sample analysis are available upon request.
} 


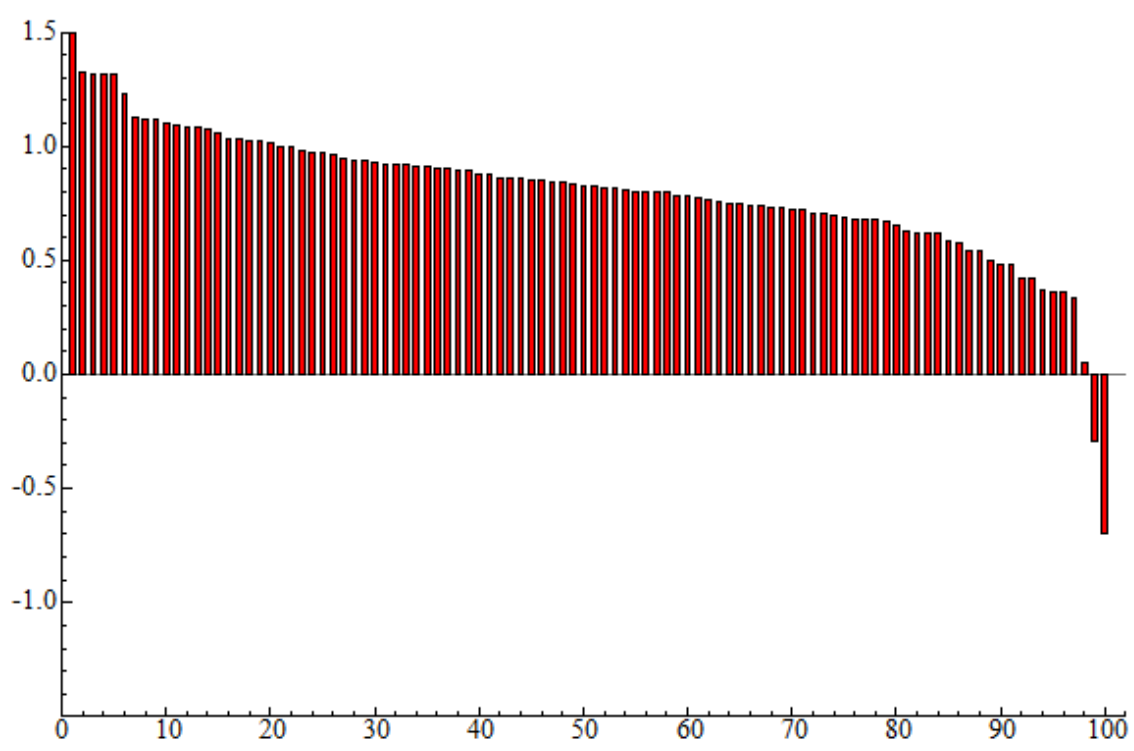

Figure 4: Estimated long-run income elasticities $\left(\beta_{y, j}\right)$ for all MSAs for full sample (1980q1-2011q4), in descending order

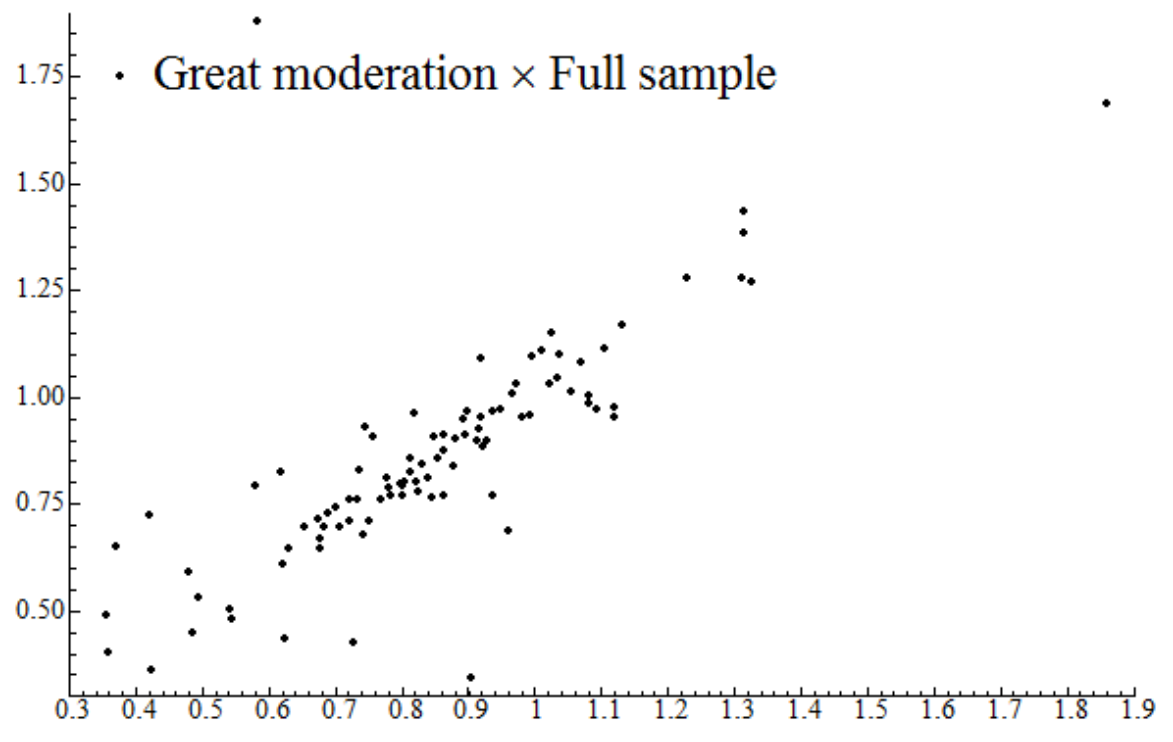

Figure 5: Estimated long-run income elasticities $\left(\beta_{y, j}\right)$ from Great moderation sample (1980q1-2007q4) versus full sample (1980q1-2011q4) 


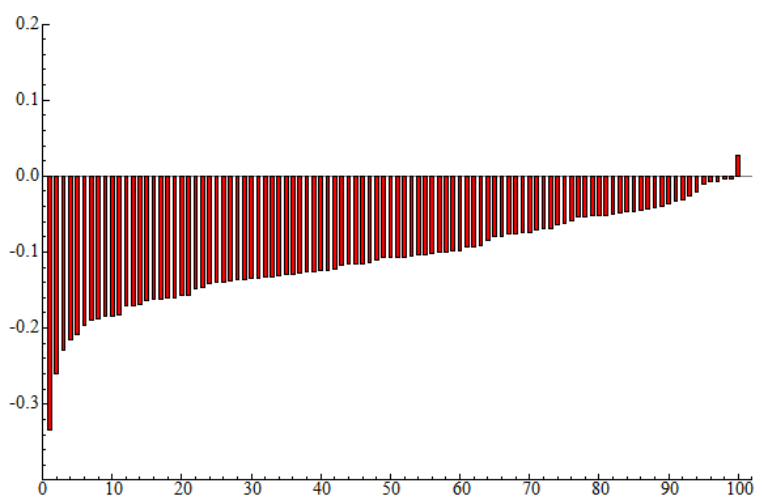

(a) $\alpha_{c}$

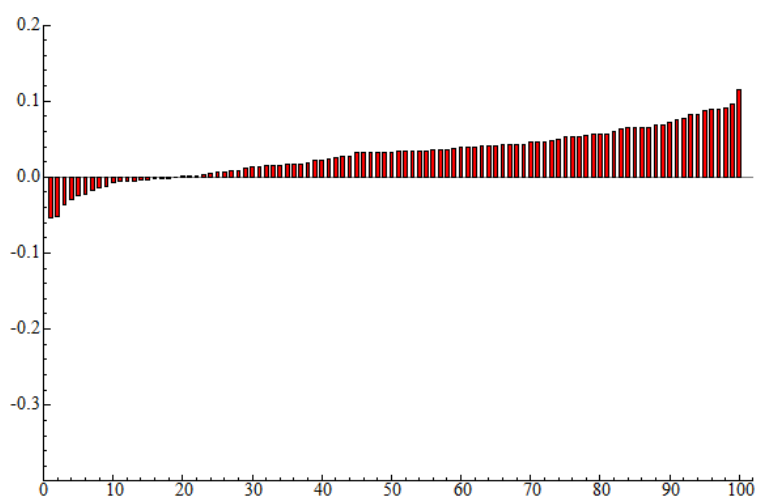

(b) $\alpha_{y}$

Figure 6: Adjustment parameter in consumption equation $\left(\alpha_{c}\right)$ and in income equation $\left(\alpha_{y}\right)$ for full sample (1980q1-2011q4), in descending order

Great Moderation sample, we see that there are no significant changes in results.

To formally explore how the inclusion of the financial crisis period affects the tests for weak exogeneity and Granger non-causality, Table 5 reports average results across the four major census regions.14

There are several interesting observations in Table 5. First, the average number of dummies retained by the IIS algorithm (confer the final column) increases slightly compared to the Great Moderation sample. Second, the main results regarding weak exogeneity and Granger causality are retained - in fact the result is further strengthened when the financial crisis period is included, i.e. the rejection of the weak implication of the PIH is stronger when we include the financial crisis period. Finally, the evidence that house prices Granger-cause consumption is stronger than what we documented for the Great Moderation sample. This is consistent with the view that the fall in house prices during the subprime crisis led to increased saving by US consumers to counteract the negative impact on their accumulated wealth of the housing crash, i.e. that there are sizeable housing wealth effects on consumption, see also Carrol et al. (2012) and Mian et al. (2013).

\footnotetext{
${ }^{14}$ Again, detailed results for the individual MSAs are available upon request.
} 


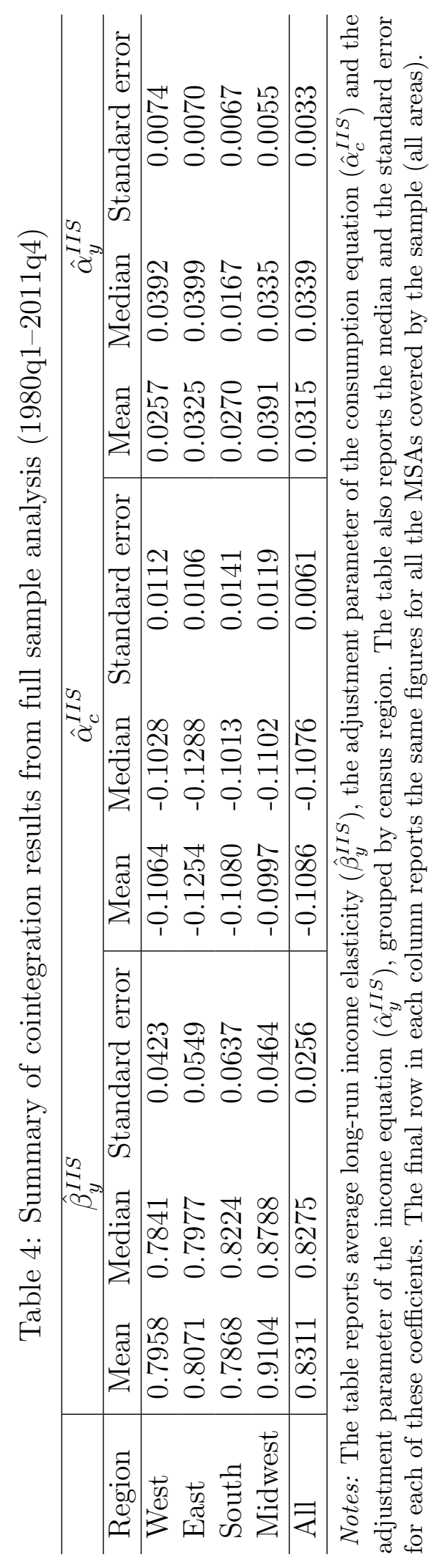


Table 5: Tests for weak exogeneity and Granger non-causality for full sample (1980q1-2011q4)

\begin{tabular}{l|cc|cc|cc|c}
\hline Region & $\alpha_{c} \neq 0$ & $\alpha_{y} \neq 0$ & $y \underset{G C}{\rightarrow} c$ & $c \underset{G C}{\rightarrow} y$ & $p h \underset{G C}{\rightarrow} c$ & $p h \underset{G C}{\rightarrow} y$ & Dummies \\
\hline West & 88.00 & 56.00 & 96.00 & 80.00 & 72.00 & 52.00 & 2.16 \\
East & 100.00 & 50.00 & 100.00 & 50.00 & 90.00 & 15.00 & 0.85 \\
South & 95.65 & 30.43 & 91.30 & 43.48 & 86.96 & 39.13 & 1.28 \\
Midwest & 83.33 & 53.33 & 93.33 & 80.00 & 76.67 & 46.67 & 2.00 \\
\hline All & 90.82 & 47.96 & 94.90 & 65.31 & 80.61 & 39.80 & 1.63 \\
\hline
\end{tabular}

Notes: Columns 2-4 report the percentage number of times where weak exogeneity of consumption $\left(\alpha_{c} \neq 0\right)$ is rejected and the percentage number of times where weak exogeneity of income $\left(\alpha_{y} \neq 0\right)$ is rejected, as well as the percentage number of times where we find that income Granger-causes consumption $(y \underset{G C}{\vec{C}} c)$ and vice versa $(c \underset{G C}{\overrightarrow{G C}} y)$. Columns 56 report the percentage number of times where we find that house prices Granger-cause consumption $(p h \underset{G C}{\vec{C}} c)$ and income $(p h \underset{G C}{\vec{G}} y)$. The final column reports the average number of dummies that were retained by the IIS algorithm. The final row in each column reports the same figures for all the MSAs covered by the sample (all areas).

\section{Macro evidence and a structural model of the VAR}

Macro time series of private income and consumption have features similar to the typical MSA series in that there are clear signs of both unit-root non-stationarity and intermittent structural breaks. In this section we present evidence of cointegration and causality which is congruent with the picture that emerged from the analysis of the MSA-data.

\subsection{Cointegration and exogeneity using aggregate US data}

Table 6 shows cointegration tests for the case where the VAR in $c_{t}$ and $y_{t}$ is of order 4 , with an unrestricted constant (allowing the necessary trends in the two variables), and a restricted deterministic trend that represents the drift in the $\mu$ parameter. This gives the same representation of deterministic trends in the VAR as in the MSA cointegration analysis. We report cointegration test results for two versions of the trace statistic: the first is for the VAR without any interventions, while the second, denoted Trace ${ }^{\mathrm{IIS}}$, is for a VAR where intervention dummies have been selected by the IIS algorithm.

IIS finds only two dummies; 1980q2 and 1981q4 15 The diagnostic tests show that the inclusion of the dummies improves the residual properties of the VAR models, so that the

\footnotetext{
${ }^{15}$ To remain consistent with the MSA analysis, a significance of $0.1 \%$ was used.
} 
Table 6: Cointegration tests from aggregate macro analysis for Great Moderation sample (1980q1-2007q4)

\begin{tabular}{ccc}
\hline$H_{0}: \operatorname{Rank}(\boldsymbol{\Pi}) \leq$ & Trace & Trace $^{\mathrm{IIS}}$ \\
\hline 0 & $45.7^{*}$ & $51.5^{*}$ \\
1 & 16.0 & $22.0^{*}$ \\
VAR diagnostics & p-values: & \\
\hline AR $^{v}$ & 0.02 & 0.91 \\
Het $^{v}$ & 0.001 & 0.72 \\
Norm $^{v}$ & 0.001 & 0.53 \\
\hline
\end{tabular}

Notes: The table reports the results from cointegration tests on the aggregate macro data. Trace is the trace statistic for a fourth order VAR, with an unrestricted constant and a restricted trend. Trace ${ }^{\mathrm{IIS}}$ is for the same fourth order VAR, but including dummies selected by the IIS algorithm.

assumption of Gaussian disturbances that underlies the inference theory is more tenable in these models than in the VAR without interventions 16

Consistent with the average MSA results, Table 6 supports cointegration in all cases. Thus, it seems to be safe to continue under the assumption of one cointegration vector. Table 7 shows the estimated cointegration parameters and the corresponding equilibrium correction coefficients from the IIS estimations. The zero restriction on the trend coefficient in the cointegration relationship is not rejected. We found the same (non-rejection) result from the analysis of the MSA data, where the co-trending restriction was accepted in about $70 \%$ of the MSAs.

The results for the equilibrium-correction parameters show that the estimate of $\hat{\alpha}_{c}^{I I S}$ is significantly different from zero at conventional levels of significance. The same is true for $\hat{\alpha}_{y}^{I I S}$. We also tested the robustness of our results by replacing the consumption data with total retail sales (at fixed prices), i.e., the same operational definition that data availability forced on us at the MSA level. In general, this leads to the same qualitative

\footnotetext{
${ }^{16} \mathrm{AR}^{v}, \mathrm{Het}^{v}, \mathrm{Norm}^{v}$ are vector versions of tests for autocorrelation (Godfrey $(1978)$ ), heteroskedasticty (White (1980)), and normality (Doornik and Hansen (1994)), see e.g. Doornik and Hendry (2013. Ch. 11.9) for details.
} 
Table 7: Estimated cointegration parameters and equilibrium correction coefficients based on IIS results in Table 6

\begin{tabular}{llcll}
\hline$\hat{\beta}_{y}^{I I S}$ & $\hat{\beta}_{\text {trend }}^{I I S}$ & $\hat{\alpha}_{c}^{I I S}$ & $\hat{\alpha}_{y}^{I I S}$ & $H_{0}: \beta_{\text {trend }}=0$ \\
\hline 0.91 & 0.001 & -0.22 & 0.17 & $0.79[0.37]$ \\
$(0.11)$ & $(0.001)$ & $(0.06)$ & $(0.08)$ & \\
1.08 & - & -0.18 & 0.27 & imposed \\
$(0.01)$ & & $(0.06)$ & $(0.09)$ & \\
\hline
\end{tabular}

Notes: This table reports the long-run income elasticity and adjustment parameters, with standard errors in round brackets below the estimates, from a fourth order VAR in consumption and income. The VAR also contain three lags of the first difference of the log of the real house price index, and one lag of the real interest rate.

conclusions 17

As a summary, the evidence in Table 6 and Table 7 confirms that a long-run relationship between private income and consumption can be established. The estimation results for the $\alpha_{c}$ and $\alpha_{y}$ show that saving behavior is not well described by the saving for a rainy day hypothesis. Instead, the results strongly indicate that equilibrium correction is just as significant in consumption as it is in income. The macro results are robust to using total retail sales instead of personal consumption expenditure. Since we used retail sales in the MSA data set, this suggests that the results from that analysis may well have been strengthened if consumption data had been available for the MSA analysis.

Although the exclusion restriction on the linear trend in the cointegration relationship is statistically acceptable in Table 7 , it is of interest to test the robustness of the estimation result for $\alpha_{c}$ and $\alpha_{y}$ (our main parameters of interest) to a specification that allows for a break in the unconditional mean of the savings rate. Both the time graph of the savings rate, and estimation of a regime-switching model for $c_{t}-y_{t}$ suggests a possible change in the mean of the savings rate around 1993q1. To take account of a shift, we specified a

\footnotetext{
${ }^{17}$ In particular, the Trace ${ }^{I S S}$ test for no cointegration becomes 29.5 with a p-value of 1.5 when retail sales data are used. When indicators are re-selected, Autometrics keeps only the 1980q2 dummy, the results for the same long-run model as in the last row in Table 7 gives an income elasticity of 0.89 , against 1.08 when aggregate consumption data are used. The estimate using retail sales is however close to the mean MSA level estimate of 0.86 that we reported in Table 2. The same is the case for the estimated loadings, which become -0.10 for $\alpha_{c}$ and 0.05 for $\alpha_{y}$. In Table 2 , the corresponding point estimates are -0.12 and 0.03 . Detailed results for the macro analysis using retail sales data are available upon request.
} 
Table 8: Estimated adjustment parameters in a model with a structural break in the savings rate in 1993q1

\begin{tabular}{l|cc}
\hline \multicolumn{2}{c}{$\Delta c_{t}$} & $\Delta y_{t}$ \\
\hline$c_{t-1}-y_{t-1}-\mu_{T_{1} T_{2}}$ & $\begin{array}{c}-1945^{*} \\
(0.039)\end{array}$ & 0.0650 \\
VAR diagnostics & & $0.0649)$ \\
\hline AR & 0.98 & 0.09 \\
Het & 0.55 & 0.16 \\
Norm & 0.95 & 0.100 \\
$\hat{\sigma}_{c}$ & 0.41 & 0.0070 \\
$\hat{\sigma}_{y}$ & & \\
$\hat{\rho}_{c y}$ & 0.28 \\
\hline \multicolumn{2}{l}{ Maximized $\log -$ likelihood: 869.61} \\
\multicolumn{2}{l}{ Sample 1980q1-2007q4. T $T=112 . \quad$ \# of parameters: 30 } \\
\hline
\end{tabular}

Notes: The table shows estimated reduced form equilibrium correction parameters $\left(\alpha_{c}\right.$ and $\left.\alpha_{y}\right)$ in a cointegrated VAR model of $\Delta c_{t}$ and $\Delta y_{t}$. Additional regressors: Three lags in $\Delta c_{t}, \Delta y_{t}$ and in real house price growth, the lagged real interest rate, impulse dummies for 1980q2 and 1981q4, as well as a differenced step dummy and a constant term.

step-function that reduces the unconditional expectation of the savings rate permanently by 3 percentage points, beginning in 1993q118

Table 8 shows the two estimated (reduced form) parameters $\alpha_{c}$ and $\alpha_{y}$ in a cointegrated VAR model that allows for the hypothesized change in the mean of the savings rate (hence $\beta_{y}=1$ is imposed in this model). We observe that the estimated $\alpha_{c}$ is similar to the estimates in Table 7, but that $\alpha_{y}$ is smaller and insignificantly different from zero.

As can be expected from Table 6, the VAR diagnostics do not give any proof of misspecification (in Table 8, we give the equation-specific diagnostics, but the vector versions of the tests give the same conclusion). Formally, we can therefore reject weak exogeneity of consumption with respect to the savings rate, but weak exogeneity of income cannot be rejected on the basis of this model.

Table 8 also shows that the VAR disturbances are positively correlated, with a correlation coefficient of 0.28 . Although the correlation is not very high, it suggests that impulse multipliers are poorly identified and that it is of interest to develop a structural

\footnotetext{
${ }^{18}$ Specifically, we subtract $\mu_{\left[T_{1} T_{2}\right]}$ from $c_{t}-y_{t} . \mu_{\left[T_{1} T_{2}\right]}$ takes one value when $t<T_{1}$ and $t>T_{2}$ and another when $\left(T_{1}, T_{2}\right)=\left(1_{T_{1}, t}+1_{T_{1}+1, t} \ldots+1_{T_{2}, t}\right)$, where $1_{T_{1}+j, t}$ is an indicator equal to unity only when $t=T_{1}+j . T_{1}$ is $1993 \mathrm{q} 1$ and $T_{2}$ is the end period of the sample.
} 
model of the VAR - a point we shall return to in the next section.

\subsection{An identified macro model}

In this section, we will consider alternative models of the VAR to explore how the savings rate responds to an increase in house prices. Since the aggregate results and the MSA level results lead to similar conclusions, we restrict the current analysis to the aggregate data.

Taking the reduced form VECM as a starting point, we formulate a classical simultaneous equations model for $\Delta c_{t}$ and $\Delta y_{t}$. As identifying assumptions, we assume that $\Delta y_{t}$ is independent of $\Delta c_{t-3}$, since it is plausible that an aggregate demand shock affects consumption relatively fast. Second, for consumption, we reasoned that if consumption growth depends on real house price growth, that effect is unlikely to have a very long lag, and therefore we identify the consumption growth equation by omitting the third lag of real house price growth from the $\Delta c_{t}$ equation.

Based on the exactly identified model, it is easy to base further modeling on the results of Full Information Maximum Likelihood (FIML) estimation. Table 9 shows the results for the structural equilibrium correction parameters $\alpha_{c}^{\prime}$ and $\alpha_{y}^{\prime}$, with model diagnostics and the LR test for overidentifying restrictions, which is very far from rejecting the validity of the 14 restrictions ( $p$-value $=0.92)$.

Note that the FIML-estimated structural parameter $\alpha_{y}^{\prime}$ in Table 9 is higher than the OLS-estimated reduced form parameter $\alpha_{y}$ above. It is also significantly different from zero, with a t-value of -2.11 . The FIML-estimated $\alpha_{c}^{\prime}$ is highly significant, with a t-value of -7.38 . These results can also be seen in Table 10 , which shows the details of the two estimated structural equations. The model has a recursive structure, since $\Delta c_{t}$ is a variable in the identified equation for $\Delta y_{t}$, while there is no corresponding contemporaneous effect of $\Delta y$ in the consumption growth equation. The two residuals of FIML estimation are almost perfectly uncorrelated (cf. Table 9). Hence we have a recursive interpretation of the structural model, where income changes are strongly influenced by contempora- 
Table 9: Estimated equilibrium correction parameters $\alpha_{c}$ and $\alpha_{y}$ in an identified structural model of $\Delta c_{t}$ and $\Delta y_{t}$ for Great Moderation sample (1980q1-2007q4)

\begin{tabular}{ccc}
\hline & $\Delta c_{t}$ & $\Delta y_{t}$ \\
\hline$c_{t-1}-y_{t-1}-\mu_{T_{1} T_{2}}$ & $-0.1961^{* *}$ & 0.1331 \\
& $(0.0267)$ & $(0.0631)$
\end{tabular}

\begin{tabular}{|c|c|c|}
\hline Structural model diagnostics & & \\
\hline$A R^{v}$ & 0.46 & \\
\hline $\mathrm{Het}^{v}$ & 0.08 & \\
\hline Norm $^{v}$ & 0.60 & \\
\hline$\hat{\sigma}_{c}$ & 0.004 & \\
\hline$\hat{\sigma}_{y}$ & & 0.007 \\
\hline$\hat{\rho}_{c y}$ & -0.015 & \\
\hline Log-likelihood: 865.96 & & \\
\hline Test of Overidentifying restrictions: & $\chi_{i d}^{2}(14)=7.30[0.92]$ & \\
\hline Sample 1980(1)-2007(4). $\quad T=112$. & No of parameters: 16 & \\
\hline
\end{tabular}

neous changes in the largest component of aggregate demand, which in turn depends on lags of income growth and on permanent income via the equilibrium correction term.

The identifying assumptions have not involved the real interest rate, and it is included, as $R_{t-1}$, in both equations in Table $10^{19}$ The estimated coefficients are negative in the $\Delta c_{t}$ equation, and positive in the $\Delta y_{t}$ equation. However, neither of the estimates are significantly different from zero. The discussion in Romer (2006) shows that small (numerical) and statistically insignificant effects of the real interest rate on US consumption is a common finding. Since we use private disposable income, where non-labor income may capture the income effect of the interest rate, the negatively signed coefficient of the real interest rate is consistent with a substitution effect.

Since the residuals of the two FIML-estimated equations are almost uncorrelated, the impulse responses to consumption and income shocks appear to be better identified empirically than in the reduced form VAR. Specifically, since house price changes (i.e., $\left.\Delta p h_{t-1}\right)$ are estimated to affect consumption growth more strongly than income growth in Table 10, a negative shock to house prices is predicted to increase the private savings rate in the short run.

\footnotetext{
${ }^{19}$ The coefficients of $R_{t-1}$, which is measured in percent, have been multiplied by 100 for readability.
} 
Table 10: Identified structural model for Great Moderation sample (1980q12007q4)

\begin{tabular}{lcccc}
\hline & \multicolumn{3}{c}{$\Delta c_{t}$} & \multicolumn{3}{c}{$\Delta y_{t}$} \\
\hline Variable & Coefficient & Standard error & Coefficient & Standard error \\
\hline$\Delta c_{t}$ & - & - & 0.47 & 0.17 \\
$\Delta c_{t-1}$ & - & - & 0.26 & 0.12 \\
$\Delta c_{t-3}$ & 0.32 & 0.07 & - & - \\
$\Delta y_{t-1}$ & 0.13 & 0.06 & -0.16 & 0.10 \\
$\Delta y_{t-3}$ & -0.10 & 0.06 & - & - \\
$\Delta p h_{t-1}$ & 0.17 & 0.05 & 0.08 & 0.10 \\
$\Delta p h_{t-2}$ & - & - & -0.15 & 0.09 \\
$R_{t-1}$ & -0.03 & 0.03 & -0.05 & 0.04 \\
$I_{1980 q 2, t}$ & -0.03 & 0.004 & - & - \\
$I_{1981 q 4, t}$ & -0.02 & 0.004 & - & - \\
$c_{t-1}-y_{t-1}-\mu_{\left[T_{1} T_{2}\right]}$ & -0.20 & 0.03 & 0.13 & 0.06 \\
\hline
\end{tabular}

Notes: The table reports FIML estimates the equations of the identified structural model. Absolute standard errors are reported. $c_{t-1}-y_{t-1}-\mu_{\left[T_{1} T_{2}\right]}$ is the savings rate, where we allow for a shift in the equilibrium savings rate.

Figure 7 shows impulse responses to a 10 per cent negative shock to real house prices. In this simulation, in order to get a clear picture, we use a model where we have imposed the restriction that changes in the real house prices do not affect income directly, and that income does not equilibrium correct. As the estimation results in Table 10 indicate, the three restrictions are statistically acceptable. A likelihood ration test of the joint hypothesis returns a p-value of 0.06 . The responses show that both consumption and income growth falls as house price growth drops. However, consumption is more negatively affected than income. The statistical significance of the first four dynamic consumption multipliers is evident, while the income responses are smaller in absolute values. Consequently, as shown in panel c) of Figure 7, the savings rate is significantly increased by the negative house price shock. 

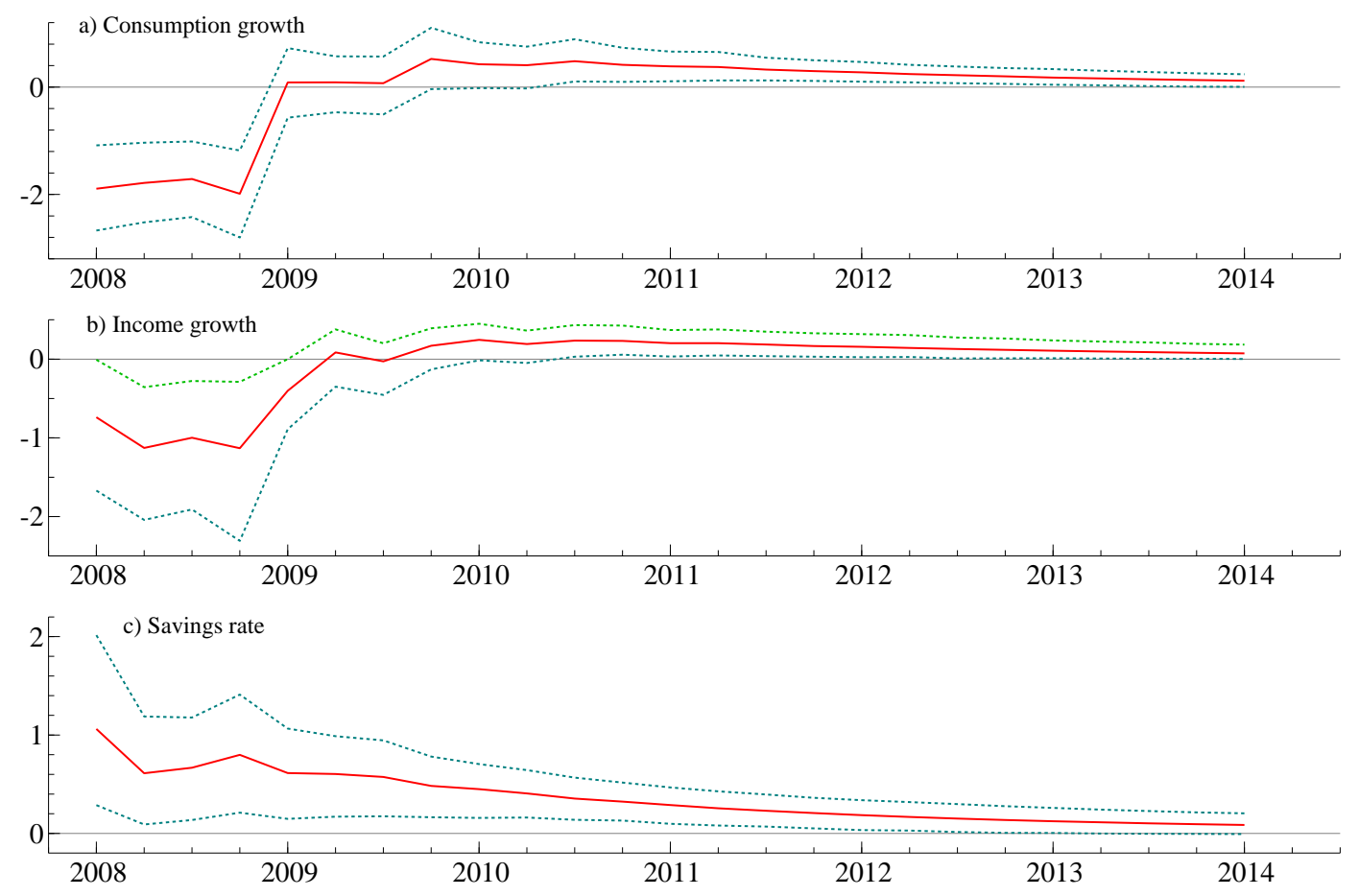

Figure 7: Impulse responses with respect to a $10 \%$ reduction in house prices, 2008q12014q1. Effects on the four quarter growth rates for consumption (panel a)) and income (panel b)), and the savings rate (panel c)), with 90\% confidence intervals.

\subsection{The macro model and the Great Recession}

The VAR in Table 8 appears to be relatively stable when the sample is extended to include 2014q1 ${ }^{20}$ We make use of the identified structural model that we used for the dynamic multipliers in Figure 7 to construct conditional forecasts for the period 2008q1-2014q1. The forecasts are reported with $95 \%$ prediction intervals. Over this 25-quarter forecast horizon, there are very few forecast failures, defined as outcomes that are not covered by the prediction intervals that reflect the forecast uncertainty "to be expected" from the estimation of the model. In fact, the only evident failures are for income growth, in

\footnotetext{
${ }^{20}$ The two estimated standard errors are practically unchanged, and the same is the case for the correlation coefficient $\left(\rho_{c y}\right)$. The mis-specification tests are insignificant, with the exception of the heteroscedasticity test, which has a p-value of 0.0043 in the $\Delta y_{t}$ equation. The estimated $\hat{\alpha}_{c}^{I I S}$ changes very little: from -0.1945 to -0.2093 , with a t-value of -5.83 . For income growth, $\hat{\alpha}_{y}^{I I S}$ is estimated at 0.0929, which is a little higher than in Table 8 but it is insignificantly different from zero also on the longest sample, with a t-value of 1.48 .
} 
$2008 \mathrm{q} 3$ and $2013 \mathrm{q} 1{ }^{21}$

The forecasts for the savings rate predict the increase that happened in 2008. Later in the forecast period, the model underpredicts consumption relative to income, but the prediction intervals contain the actuals for the length of the 25-quarter forecast period. Given that the Great Recession dominates the forecast period, it is reassuring that there are no forecast failures for 2008-2010. Based on the model in Table 10, the interpretation of the forecast performance is that there are no "new" breaks in the cointegration mean, $\mu_{T_{1} T_{2}}$, over the 2008q1-2014q1 period, and also that the estimated parameters of the model are relatively stable over the extended sample period.
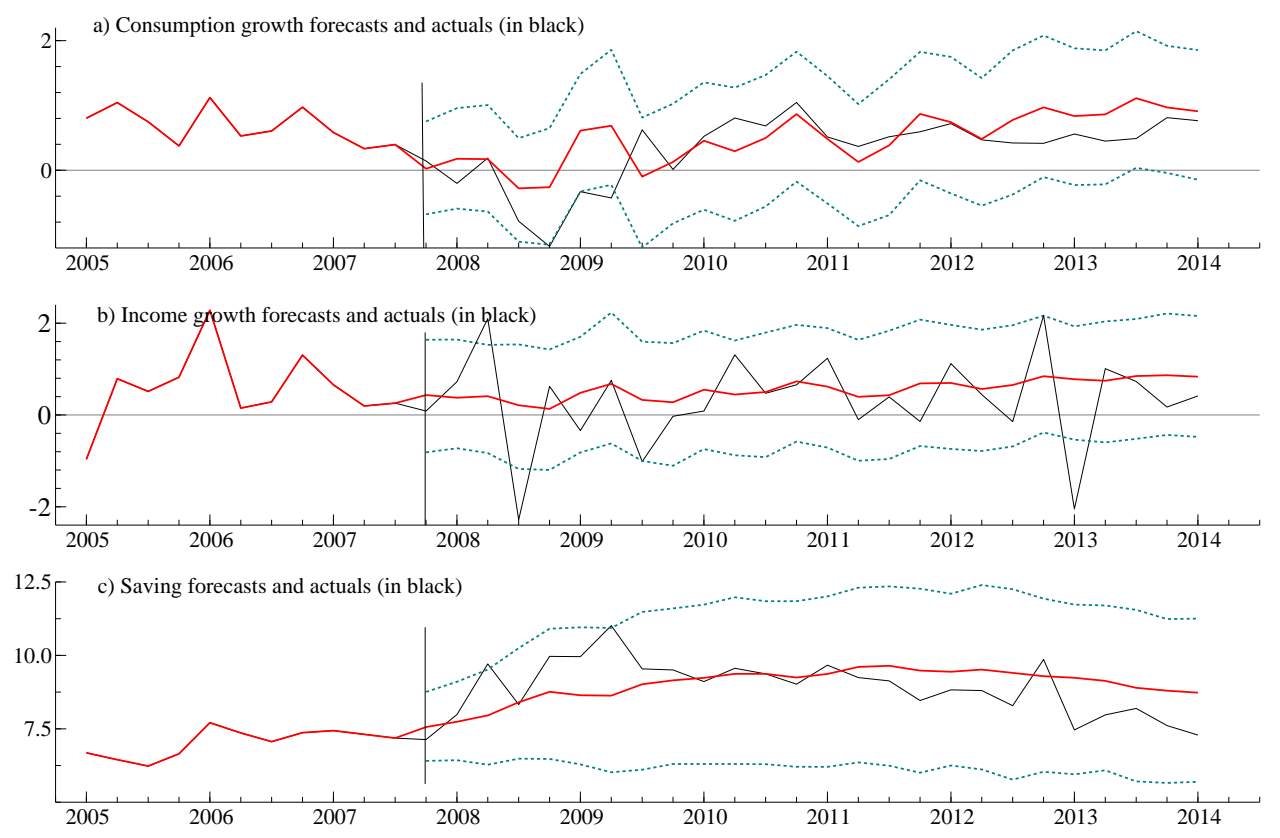

Figure 8: Dynamic forecasts based on the same model specification as in Figure 7, 2008q12014q1. The forecasts are conditional on actual real house price changes. Bounds for 95 percent prediction intervals are drawn together with the forecasts and the actuals

\footnotetext{
${ }^{21}$ In Eitrheim et al. (2002), the impact of the banking crisis in Norway in 1990 on the possibility of distinguishing empirically between the Euler-equation and the consumption function versions of the system was investigated. The results showed that it was the data from the crisis and post crisis years that made it possible to separate the two hypotheses emprically
} 


\section{Conclusion}

We started this paper by asking whether US consumers saved for a rainy day during the Great Moderation period. To test this hypothesis, we have concentrated on the so-called weak implication of the permanent income hypothesis, which entails that consumption growth does not respond to deviations from a long-run relationship between income and consumption. The statistical implication of this is that consumption is weakly exogenous with respect to any long-run cointegrating relationship that exists between income and consumption. Our econometric analysis on the Great Moderation sample (1980q12007q4) give mixed support for this hypothesis, and indicate that consumption responds to deviations from the long-run cointegrating relationship between income and consumption in a majority of the areas. Including the financial crisis period in the estimation sample, this result is strengthened, and the same is true for the results from the aggregate time series.

The VAR models that we use for testing include lagged growth rates in real house

prices. In the MSA models we find significant effects of these conditioning variables, first on the 1980q1-2007q4 sample and even stronger effects when the financial crisis and Great Recession is included. On both samples, the overall direction of the effect is that lagged house price changes are positively related to consumption growth. The macro model corroborated the existence of such a relationship. Our finding therefore suggests that the large declines in housing equity in the aftermath of the subprime crash have strongly dampened consumer spending in the US. A similar conclusion is reached by Aron et al. (2012), Carrol et al. (2012) and Mian et al. (2013).

Our main research question has been joint modeling of income and consumption, which is also central in the discussion of the effectiveness of fiscal stimulus. Although there is nothing in our empirical analysis that calls into question the importance of sustainable fiscal policies, the direction of causality has relevance for the argument often raised against fiscal stimulus: the intended effects of a stimulus are largely offset by 
Ricardian equivalence effects, crowding out private consumption. This, together with the central bank response, lead to low-valued fiscal multipliers.

Our econometric results have most direct bearing on the Ricardian equivalence premise. We give proof that US private consumption growth was positively related to lagged income before the crisis, and that the relationship may even be stronger on the sample that includes the Great recession. Crowding out is mainly a concern when there is little spare capacity (and then discretionary fiscal policy should not be used). With interest rates at or near the zero lower bound, fiscal stimulus will not be met by interest rate increases (if we keep deflation out of the picture).

Another relevant question concerns the effects of de-leveraging (private financial consolidation). As documented by Jordà et al. (2013) financial recessions with high debt-toincome ratios are deeper and slower in recovery than "normal" recessions. That does not imply that fiscal multipliers are low in these recessions, and the analysis of DeLong and Summers (2012) points in the opposite direction, that the fiscal multiplier is likely to be high in the situation that the US has been in during the Great Recession. The point is that de-leveraging and financial consolidation represent so much "negative stimulus" that they for a long time dominated the effects of expansionary fiscal policy ${ }^{22}$ Although we have not addressed these important issues directly (the parameters in the models we have estimated are neither regime-dependent nor state-contingent), the results that we obtain on the full sample analysis suggest that the responsiveness of consumption to income has increased, rather than decreased, during the Great Recession.

\footnotetext{
${ }^{22}$ As was also seen in Norway in the recession that followed the banking crisis of 1989, cf. Eika and Nymoen (1992).
} 


\section{References}

Aizenman, J. and I. Noy (2013). Macroeconomic Adjustments and the History of Crises in Open Economies. Journal of International Money and Finance, 38(C), 41-58.

Alan, S., T. Crossley and H. Low (2012). Saving on a rainy day, borrowing for a rainy day. IFS Working Papers 11.

Aron, J., J. V. Duca, J. Muellbauer, K. Murata and A. Murphy (2012). Credit, Housing Collateral and Consumption: Evidence from the UK, Japan and the US. Review of Income and Wealth, 58(3), 397-423.

Attanasio, O. (1999). Consumption. In Taylor, J. and M. Woodford (eds.), Handbook in Macroeconomics, vol. Volume 1B, chap. 11, 741-812. Elsevier.

Attanasio, O. P. and G. Weber (2010). Consumption and Saving: Models of Intertemporal Allocation and Their Implications for Public Policy. Journal of Economic Literature, 48(3), pp. 693-751.

Campbell, J. Y. (1987). Does Saving Anticipate Declining Labor Income? An Alternative Test of the Permanent Income Hypothesis. Econometrica, 55, 1249-73.

Campbell, J. Y. and N. G. Mankiw (1989). Consumption, Income and Interest Rates: Reinterpreting the Time Series Evidence. In Blanchard, O. J. and S. Fisher (eds.), NBER Macroeconomics Annual 1989, 185-216. MIT Press, Cambridge, Mass.

Carrol, C., J. Slacalek and M. Sommer (2012). Dissecting saving dynamics: measuring credit, wealth and precautionary effects. Mimeo, John Hopkins University.

Carroll, C. (1992). The Buffer-Stock Theory of Saving: Some Macroeconomic Evidence. Brookings Papers on Economic Activity, 23(2), 61-156.

Carroll, C. (2009). Precautionary Saving and the Marginal Propensity to Consume Out of Permanent Income. Journal of Monetary Economics, 56(6), 780-790. 
Case, K. E., , J. M. Quigley and R. J. Shiller (2012). Wealth Effects Revisited 1975-2012. Critical Finance Review, 2, 101-128.

Castle, J. L., J. A. Doornik and D. F. Hendry (2012). Model Selection when there are Multiple Breaks. Journal of Econometrics, 169(2), 239-246.

Davidson, J. E. H., D. F. Hendry, F. Srba and S. Yeo (1978). Econometric Modelling of the Aggregate Time-Series Relationship between Consumers' Expenditure and Income in the United Kingdom. Economic Journal, 88, 661-692.

Deaton, A. (1992). Understanding Consumption. Claredon Press, Oxford.

Dejuan, J. P., J. J. Seater and T. S. Wirjanto (2004). A Direct Test of the Permanent Income Hypothesis with an Application to the U.S. States. Journal of Money, Credit and Banking, 36(6), 1091-1103.

DeLong, J. and L. Summers (2012). Fiscal Policy in a Depressed Economy. Brookings Papers on Economic Activity, 2012, 233-274.

Dickey, D. A. and W. A. Fuller (1979). Distribution of the Estimators for Autoregressive Time Series With a Unit Root. Journal of the American Statistical Association, $74(366), 427-431$.

Doornik, J. (2009). Autometrics. In Castle, J. L. and N. Shephard (eds.), The Methodology and Practice of Econometrics, 88-121. Oxford University Press.

Doornik, J. A. and H. Hansen (1994). A Practical Test of Multivariate Normality. Unpublished paper, Nuffield College.

Doornik, J. A. and D. F. Hendry (2013). Modelling Dynamic Systems PcGive 14. Volume 2. Timberlake Consultants, London.

Eberly, J. (2014). Defining the Reemerging Role of Fiscal Policy. In Akerlof, G., O. Blanchard, D. Roemer and J. Stiglitz (eds.), What Have We Learned? Macroeconomic Policy after the Crisis., chap. 14. MIT Press. 
Eggertsson, G. B. and P. Krugman (2012). Debt, Deleveraging, and the Liquidity Trap: A Fisher-Minsky-Koo Approach. The Quarterly Journal of Economics, 127(3), 14691513.

Eika, K. H. and R. Nymoen (1992). Finansiell konsolidering som en konjunkturfaktor [Financial Consolidation as a Business Cycle Factor]. Penger og Kreditt, 21(1), 29-38.

Eitrheim, Ø., E. S. Jansen and R. Nymoen (2002). Progress from Forecast Failure: The Norwegian Consumption Function. Econometrics Journal, 5. Forthcoming.

Engle, R. F. and C. W. J. Granger (1987). Co-Integration and Error Correction: Representation, Estimation and Testing. Econometrica, 55(2), 251-276.

Engle, R. F., D. F. Hendry and J.-F. Richard (1983). Exogeneity. Econometrica, 51, $277-304$.

Godfrey, L. G. (1978). Testing for Higher Order Serial Correlation When the Regressors Include Lagged Dependent Variables. Econometrica, 46, 1303-1313.

Granger, C. W. J. (1986). Developments in the study of cointegrated economic variables. Oxford Bulletin of Economics and Statistics, 48(3), 213-228.

Guerrieri, V. and G. Lorenzoni (2011). Credit Crises, Precautionary Savings, and the Liquidity Trap. NBER Working Papers 17583, NBER.

Hall, R. E. (1978). Stochastic implications of the life cycle permanent income hypothesis. Journal of Political Economy, 86, 971-987.

Hall, R. E. (2011). The long slump. American Economic Review, 101 (2), 461-469.

Harbo, I., S. Johansen, B. Nielsen and A. Rahbek (1998). Asymptotic Inference on Cointegrating Rank in Partial Systems. Journal of Business and Economic Statistics, $16,388-399$. 
Haug, A. (1996). Blanchard's Model of Consumption: An Empirical Study. Journal of Business and Economic Statistics, 14, 169-177.

Hendry, D. F. (1995). Dynamic Econometrics. Oxford University Press, Oxford.

Hendry, D. F. and J. Doornik (2009). Empirical Econometric Modelling using PcGive: Volume I. Timberlake Consultant Press, London.

Hendry, D. F., S. Johansen and C. Santos (2008). Automatic selection of indicators in a fully saturated regression. Computational Statistics, 33, 317-335.

Hendry, D. F. and T. von Ungern-Sternberg (1981). Liquidity and Inflation Effects on Consumer Expenditure. In Deaton, A. (ed.), Essays in the Theory and Measurement of Consumers' Behaviour. Cambridge University Press, Cambridge.

Jappelli, T. and L. Pistaferri (2010). The Consumption Response to Income Changes. Annual Review of Economics, 2, 479-506.

Johansen, S. (1988). Statistical analysis of cointegration vectors. Journal of Economic Dynamics and Control, 12, 231-254.

Johansen, S. (1992). Cointegration in Partial Systems and the Efficiency of SingleEquation Analysis. Journal of Econometrics, 52, 389-402.

Johansen, S. (1994). Testing Weak Exogeneity and the Order of Cointegration in U.K. Money Demand Data. In Ericsson, N. R. and J. S. Irons (eds.), Testing Exogeneity, chap. 5, 121-143. Oxford University Press.

Johansen, S. (1995). Likelihood-Based Inference in Cointegrated Vector Autoregressive Models. Oxford University Press.

Johansen, S. and B. Nielsen (2009). An analysis of the indicator saturation estimator as a robust regression estimator. In Castle, J. L. and N. Shepard (eds.), The Methodology and Practice of Econometrics, 1-36. Oxford University Press. 
Jordà, O., M. Schularick and A. Taylor (2013). When Credit Bites Back. Journal of Money Credit and Banking, 45(s2), 3-28.

Ljungqvist, L. and T. Sargent (2004). Recursive Macroeconimic Theory. MIT Press, 2nd edn.

Mian, A., K. Rao and A. Sufi (2013). Household Balance Sheets, Consumption, and the Economic Slump. The Quarterly Journal of Economics, 128(4), 1687-1726.

Muellbauer, J. and R. Lattimore (1995). The Consumption Function: A Theoretical and Emprical Overview. In M.H., P. and M. Wickens (eds.), Handbook of Applied Economterics, vol. 1: Macroeconomics, chap. 5, 221-311. Blackwell.

Parker, J. A. (2000). Spendthrift in America? On two decades of decline in the U.S. saving rate. In Bernanke, B. S. and J. J. Rotemberg (eds.), NBER Macroeconomics Annual 1999, chap. vol. 14, 317-387. NBER.

Romer, D. (2006). Advanced Macroeconomics. McGraw-Hill, New York, 3rd edn.

Sorensen, B. E. and M. J. Luengo-Prado (2008). What can explain excess smoothness and sensitivity of state-level consumption? Review of Economics and Statistics, 90(1), $65-88$.

Stiglitz, J. E. (2014). The Lessons from the North Atlantic Crisis for Economic Theory and Policy. In Akerlof, G., O. Blanchard, D. Roemer and J. Stiglitz (eds.), What Have We Learned? Macroeconomic Policy after the Crisis., chap. 29. MIT Press.

Tversky, A. and D. Kahneman (1992). Advances in Prospect Theory: Cumulative Representation of Uncertainty. Journal of Risk and Uncertainty, 5(4), 297-323.

White, J. (1980). A Heteroskedasticity-Consistent Covariance Matrix Estimator and a Direct Test of Heteroskedasticity. Econometrica, 48, 817-838. 


\section{Appendix A: Detailed econometric results by MSA}

Table A.1: Specification results for West region for Great Moderation sample (1980q1-2007q4)

\begin{tabular}{|c|c|c|c|c|c|c|c|c|c|c|c|}
\hline MSA and state & Dum. & $p^{*}$ & $\operatorname{Rank}\left(\boldsymbol{\Pi}_{i}\right)$ & Auto. & Norm. & Hetero. & $\mathrm{p}($ co-trend $)$ & $p(y \underset{G C}{\rightarrow} c)$ & $p(c \underset{G C}{\rightarrow} y)$ & $\mathrm{p}(\mathrm{c}$ is $\mathrm{WE})$ & $\mathrm{p}(\mathrm{c}$ is WE) \\
\hline ALBUQUERQUE NM & 2 & 4 & 1 & 0 & 0.0103 & 0.0109 & 0.0115 & 0.0014 & 0.0306 & 0.0002 & 0.1989 \\
\hline BOISE CITY ID & 0 & 3 & 0 & 0 & 0.8509 & 0.4119 & 0.0003 & 0.0000 & 0.3359 & 0.0679 & 0.3718 \\
\hline BOULDER CO & 1 & 2 & 0 & 0 & 0.3398 & 0.0001 & 0.0309 & 0.0672 & 0.0007 & 0.0668 & 0.3512 \\
\hline COLORADO SPRINGS CO & 0 & 4 & 0 & 0 & 0.4796 & 0.0514 & 0.1020 & 0.1292 & 0.0562 & 0.0320 & 0.1642 \\
\hline DENVER CO & 3 & 4 & 1 & 0 & 0.3605 & 0.0191 & 0.0149 & 0.3252 & 0.0002 & 0.0378 & 0.0029 \\
\hline EUGENE OR & 0 & 2 & 0 & 0 & 0.8916 & 0.0217 & 0.6806 & 0.0004 & 0.0106 & 0.0059 & 0.6275 \\
\hline HONOLULU HI & 3 & 5 & 0 & 0 & 0.2232 & 0.6954 & 0.7968 & 0.0018 & 0.2537 & 0.0016 & 0.0613 \\
\hline LAS VEGAS NV & 1 & 2 & 0 & 0 & 0.3395 & 0.0853 & 0.9441 & 0.0000 & 0.0018 & 0.0000 & 0.5725 \\
\hline LOS ANGELES CA & 0 & 2 & 0 & 0 & 0.0179 & 0.4055 & 0.2302 & 0.0002 & 0.0306 & 0.0035 & 0.1340 \\
\hline OAKLAND CA & 0 & 4 & 0 & 0 & 0.0291 & 0.8735 & 0.9961 & 0.0002 & 0.1637 & 0.0001 & 0.5081 \\
\hline OXNARD CA & 1 & 4 & 2 & 0 & 0.0260 & 0.9213 & 0.0516 & 0.0065 & 0.0241 & 0.0484 & 0.0150 \\
\hline PHOENIX AR & 3 & 5 & 1 & 1 & 0.0926 & 0.3568 & 0.0103 & 0.0005 & 0.0001 & 0.0002 & 0.4662 \\
\hline PORTLAND WA OR & 3 & 5 & 0 & 0 & 0.8188 & 0.1349 & 0.3975 & 0.0065 & 0.0001 & 0.0015 & 0.0610 \\
\hline PROVO UT & 1 & 3 & 1 & 0 & 0.7068 & 0.1967 & 0.3203 & 0.0000 & 0.6577 & 0.0000 & 0.3591 \\
\hline RIVERSIDE CA & 0 & 4 & 1 & 0 & 0.0048 & 0.1145 & 0.0013 & 0.0040 & 0.0066 & 0.2653 & 0.0042 \\
\hline SACRAMENTO CA & 0 & 4 & 0 & 0 & 0.0117 & 0.0272 & 0.2635 & 0.0012 & 0.0258 & 0.0747 & 0.1743 \\
\hline SALT LAKE CITY UT & 0 & 4 & 1 & 0 & 0.3075 & 0.0211 & 0.1709 & 0.2847 & 0.0020 & 0.1471 & 0.0009 \\
\hline SAN DIEGO CA & 4 & 5 & 1 & 0 & 0.0305 & 0.7672 & 0.0386 & 0.0006 & 0.0049 & 0.0001 & 0.1203 \\
\hline SAN FRANCISCO CA & 1 & 3 & 2 & 0 & 0.3442 & 0.1475 & 0.5919 & 0.0000 & 0.2099 & 0.0000 & 0.3462 \\
\hline SAN JOSE CA & 0 & 2 & 1 & 0 & 0.1294 & 0.0066 & 0.4972 & 0.0000 & 0.0092 & 0.0004 & 0.0179 \\
\hline SANTA ANA CA & 0 & 2 & 0 & 0 & 0.1221 & 0.5841 & 0.7936 & 0.0002 & 0.0140 & 0.0074 & 0.7711 \\
\hline SEATTLE WA & 2 & 4 & 1 & 0 & 0.1915 & 0.0708 & 0.0874 & 0.0000 & 0.0185 & 0.0000 & 0.4810 \\
\hline SPOKANE WA & 2 & 4 & 1 & 1 & 0.4852 & 0.5537 & 0.0000 & 0.0021 & 0.0507 & 0.0001 & 0.5549 \\
\hline TACOMA WA & 2 & 4 & 1 & 0 & 0.5206 & 0.2186 & 0.0000 & 0.0006 & 0.0164 & 0.0000 & 0.2915 \\
\hline TUCSON AZ & 1 & 2 & 0 & 0 & 0.5584 & 0.0299 & 0.1001 & 0.0000 & 0.0000 & 0.0015 & 0.8566 \\
\hline
\end{tabular}

Notes: This table reports supplementary results for the MSAs in our sample that are situated in the West region of the US. The first three columns report the number of dummies picked up by the IIS algorithm, Dum., the selected lag length (based on AIC), $p_{i}^{*}$, and the cointegration rank, Rank (ח). The next three columns report the p-value from tests for no autocorrelation (Auto.), normality (Norm.) and homoskedasticity (Hetero.). The next column reports the p-value for the test of whether the trend can be excluded from the cointegration space, $\mathrm{p}$ (co-trend). The final four columns report p-values from tests for GC from income to consumption $(p(y \overrightarrow{G C} c))$, GC from consumption to income $(p(c \overrightarrow{G C} y))$, as well as tests for weak exogeneity of consumption, $\mathrm{p}(\mathrm{c}$ is WE), and income, $\mathrm{p}(\mathrm{y}$ is WE).

Table A.2: Specification results for East region for Great Moderation sample (1980q1-2007q4)

\begin{tabular}{|c|c|c|c|c|c|c|c|c|c|c|c|}
\hline MSA and state & Dum. & $p^{*}$ & $\operatorname{Rank}\left(\boldsymbol{\Pi}_{i}\right)$ & Auto. & Norm. & Hetero. & $\mathrm{p}($ co-trend $)$ & $p(y \underset{G C}{\rightarrow} c)$ & $p(c \underset{G C}{\rightarrow} y)$ & $\mathrm{p}(\mathrm{c}$ is $\mathrm{WE})$ & $\mathrm{p}(\mathrm{c}$ is $\mathrm{WE})$ \\
\hline ALBANY NY & 4 & 4 & 2 & 0 & 0.1599 & 0.0274 & 0.0320 & 0.0001 & 0.0553 & 0.0000 & 0.7277 \\
\hline BOSTON MA & 1 & 4 & 2 & 0 & 0.7274 & 0.0920 & 0.0177 & 0.0000 & 0.4283 & 0.0000 & 0.0865 \\
\hline BRIDGEPORT CT & 0 & 4 & 2 & 1 & 0.3164 & 0.1297 & 0.7031 & 0.0014 & 0.2182 & 0.0000 & 0.1386 \\
\hline BUFFALO NY & 3 & 4 & 2 & 0 & 0.0341 & 0.2864 & 0.0658 & 0.0002 & 0.5491 & 0.0000 & 0.1367 \\
\hline CAMBDEN NJ & 0 & 3 & 1 & 0 & 0.0419 & 0.2339 & 0.0862 & 0.1451 & 0.0215 & 0.0214 & 0.0223 \\
\hline EDISON NJ & 0 & 2 & 0 & 0 & 0.0922 & 0.6880 & 0.8140 & 0.0014 & 0.1297 & 0.0003 & 0.3463 \\
\hline HARRISBURG PA & 1 & 4 & 0 & 0 & 0.2906 & 0.5605 & 0.6022 & 0.0594 & 0.1687 & 0.0440 & 0.0155 \\
\hline HARTFORD CT & 0 & 2 & 1 & 0 & 0.1504 & 0.5168 & 0.2191 & 0.0000 & 0.0575 & 0.0000 & 0.5067 \\
\hline MANCHESTER NH & 1 & 4 & 2 & 0 & 0.4988 & 0.7038 & 0.0020 & 0.0121 & 0.0864 & 0.0011 & 0.2890 \\
\hline NASSAU NY & 0 & 4 & 1 & 0 & 0.1288 & 0.0300 & 0.6200 & 0.0003 & 0.0667 & 0.0000 & 0.1326 \\
\hline NEWARK PA NJ & 2 & 4 & 1 & 0 & 0.0794 & 0.0015 & 0.0061 & 0.0220 & 0.0162 & 0.0008 & 0.0228 \\
\hline NEW HAVEN CT & 0 & 2 & 2 & 0 & 0.0766 & 0.0296 & 0.0001 & 0.0463 & 0.0009 & 0.0231 & 0.0650 \\
\hline NEW YORK NJ NY & 1 & 4 & 1 & 0 & 0.0100 & 0.0508 & 0.1114 & 0.0124 & 0.0364 & 0.0005 & 0.0560 \\
\hline OCEAN CITY NJ & 0 & 5 & 0 & 0 & 0.1530 & 0.3429 & 0.5828 & 0.0121 & 0.0213 & 0.0003 & 0.0395 \\
\hline PHILADELPHIA PA & 0 & 4 & 1 & 0 & 0.1743 & 0.0350 & 0.6466 & 0.0002 & 0.3670 & 0.0000 & 0.1142 \\
\hline PITTSBURG PA & 0 & 4 & 2 & 1 & 0.0657 & 0.7750 & 0.1373 & 0.0009 & 0.0119 & 0.0023 & 0.0037 \\
\hline PORTLAND ME & 2 & 4 & 0 & 1 & 0.0076 & 0.2179 & 0.2902 & 0.0001 & 0.0000 & 0.0002 & 0.2555 \\
\hline PROVIDENCE MA RI & 1 & 5 & 2 & 0 & 0.0840 & 0.5420 & 0.5470 & 0.0000 & 0.2023 & 0.0000 & 0.9938 \\
\hline SYRACUSE NY & 2 & 5 & 2 & 0 & 0.5756 & 0.5734 & 0.0678 & 0.3602 & 0.0018 & 0.0428 & 0.0006 \\
\hline TRENTON NJ & 1 & 5 & 0 & 0 & 0.0277 & 0.0217 & 0.2903 & 0.0062 & 0.6963 & 0.0001 & 0.8868 \\
\hline
\end{tabular}

Notes: This table reports supplementary results for the MSAs in our sample that are situated in the East region of the US. The first three columns report the number of dummies picked up by the IIS algorithm, Dum., the selected lag length (based on AIC), $p_{i}^{*}$, and the cointegration rank, Rank ( $\Pi$ ). The next three columns report the p-value from tests for no autocorrelation (Auto.), normality (Norm.) and homoskedasticity (Hetero.). The next column reports the p-value for the test of whether the trend can be excluded from the cointegration space, $\mathrm{p}$ (co-trend). The final four columns report p-values from tests for GC from income to consumption $(p(y \overrightarrow{G C})$ ) , GC from consumption to income $(p(c \underset{G C}{\rightarrow} y))$, as well as tests for weak exogeneity of consumption, $\mathrm{p}(\mathrm{c}$ is WE), and income, $\mathrm{p}(\mathrm{y}$ is WE). 
Table A.3: Specification results for South region for Great Moderation sample (1980q1-2007q4)

\begin{tabular}{|c|c|c|c|c|c|c|c|c|c|c|c|}
\hline MSA and state & Dum. & $p^{*}$ & $\operatorname{Rank}\left(\boldsymbol{\Pi}_{i}\right)$ & Auto. & Norm. & Hetero. & $\mathrm{p}($ co-trend $)$ & $p(y \underset{G C}{\rightarrow} c)$ & $p(c \underset{G C}{\rightarrow} y)$ & $\mathrm{p}(\mathrm{c}$ is $\mathrm{WE})$ & $\mathrm{p}(\mathrm{c}$ is $\mathrm{WE})$ \\
\hline ATLANTA GA & 0 & 5 & 1 & 1 & 0.3973 & 0.0206 & 0.8540 & 0.0000 & 0.0039 & 0.0000 & 0.3548 \\
\hline AUSTIN TX & 0 & 4 & 1 & 0 & 0.1777 & 0.6882 & 0.2591 & 0.3773 & 0.0067 & 0.5415 & 0.0012 \\
\hline BALTIMORE MD & 1 & 4 & 1 & 0 & 0.8937 & 0.0304 & 0.9189 & 0.0004 & 0.0210 & 0.0004 & 0.0173 \\
\hline BIRMINGHAM AL & 2 & 4 & 1 & 0 & 0.5956 & 0.8325 & 0.0024 & 0.0013 & 0.0755 & 0.0000 & 0.0855 \\
\hline CHARLOTTE SC NC & 0 & 5 & 0 & 0 & 0.5774 & 0.0105 & 0.0389 & 0.0031 & 0.0059 & 0.0004 & 0.6380 \\
\hline CINCINNATI IN KY OH & 1 & 5 & 1 & 0 & 0.6294 & 0.3343 & 0.0000 & 0.0019 & 0.0351 & 0.0001 & 0.4045 \\
\hline COLUMBUS OH & 1 & 4 & 0 & 0 & 0.1028 & 0.8631 & 0.1255 & 0.4981 & 0.0030 & 0.4700 & 0.0025 \\
\hline FORT LAUDERDALE FL & 1 & 4 & 0 & 0 & 0.2260 & 0.0879 & 0.0838 & 0.0421 & 0.0000 & 0.1983 & 0.1645 \\
\hline FORT WORTH TX & 2 & 5 & 0 & 0 & 0.8956 & 0.1123 & 0.0001 & 0.4677 & 0.0156 & 0.7868 & 0.1840 \\
\hline GREENSBORO NC & 1 & 4 & 2 & 0 & 0.2081 & 0.0110 & 0.3452 & 0.0000 & 0.0323 & 0.0002 & 0.3887 \\
\hline GREENVILLE SC & 0 & 5 & 0 & 0 & 0.6273 & 0.6890 & 0.5203 & 0.2149 & 0.0000 & 0.3552 & 0.0117 \\
\hline HOUSTON TX & 1 & 4 & 1 & 0 & 0.2910 & 0.0067 & 0.2975 & 0.0014 & 0.3384 & 0.0000 & 0.2514 \\
\hline JACKSONVILLE FL & 1 & 4 & 1 & 0 & 0.1296 & 0.0859 & 0.9530 & 0.0048 & 0.0004 & 0.0020 & 0.0632 \\
\hline LITTLE ROCK AR & 1 & 2 & 1 & 0 & 0.3998 & 0.3866 & 0.0001 & 0.0074 & 0.0599 & 0.0290 & 0.1738 \\
\hline LOUISVILLE IN KY & 2 & 4 & 1 & 1 & 0.9315 & 0.0217 & 0.0298 & 0.0011 & 0.2200 & 0.0000 & 0.7647 \\
\hline MIAMI FL & 1 & 2 & 0 & 0 & 0.6370 & 0.0845 & 0.0119 & 0.0106 & 0.0767 & 0.1217 & 0.1615 \\
\hline NASHVILLE TN & 3 & 4 & 1 & 1 & 0.1253 & 0.2128 & 0.0074 & 0.0000 & 0.0278 & 0.0000 & 0.9145 \\
\hline NEW ORLEANS LA & 4 & 5 & 1 & 0 & 0.9932 & 0.0196 & 0.0001 & 0.0000 & 0.0000 & 0.0000 & 0.0596 \\
\hline OKLAHOMA CITY OK & 0 & 4 & 0 & 1 & 0.0292 & 0.7237 & 0.4756 & 0.0672 & 0.0064 & 0.1961 & 0.0030 \\
\hline ORLANDO FL & 1 & 4 & 0 & 0 & 0.6321 & 0.2338 & 0.9553 & 0.0033 & 0.0004 & 0.0014 & 0.9000 \\
\hline RALEIGH NC & 1 & 4 & 1 & 0 & 0.7733 & 0.0037 & 0.2577 & 0.0020 & 0.0019 & 0.0003 & 0.0616 \\
\hline RICHMOND VA & 2 & 4 & 2 & 1 & 0.7581 & 0.1660 & 0.0124 & 0.1376 & 0.0000 & 0.1919 & 0.0000 \\
\hline SAN ANTONIO TX & 1 & 5 & 1 & 0 & 0.0285 & 0.4152 & 0.7532 & 0.0591 & 0.0008 & 0.2144 & 0.0008 \\
\hline TAMPA FL & 1 & 5 & 2 & 1 & 0.8343 & 0.6185 & 0.0029 & 0.0201 & 0.0001 & 0.0051 & 0.0024 \\
\hline VIRGINIA BEACH NC VA & 2 & 4 & 2 & 1 & 0.2372 & 0.1002 & 0.4099 & 0.0000 & 0.2025 & 0.0000 & 0.6672 \\
\hline WASHINGTON WV MD VA & 2 & 5 & 2 & 0 & 0.2187 & 0.0267 & 0.0617 & 0.0000 & 0.2336 & 0.0000 & 0.7320 \\
\hline WEST PALM BEACH FL & 1 & 4 & 1 & 0 & 0.2073 & 0.0864 & 0.1882 & 0.0068 & 0.0004 & 0.0002 & 0.1026 \\
\hline WILMINGTON NJ MD DE & 0 & 4 & 1 & 0 & 0.3825 & 0.6878 & 0.4495 & 0.0000 & 0.2027 & 0.0000 & 0.0874 \\
\hline
\end{tabular}

Notes: This table reports supplementary results for the MSAs in our sample that are situated in the South region of the US. The first three columns report the number of dummies picked up by the IIS algorithm, Dum., the selected lag length (based on AIC), $p_{i}^{*}$, and the cointegration rank, Rank (ח). The next three columns report the p-value from tests for no autocorrelation (Auto.), normality (Norm.) and homoskedasticity (Hetero.). The next column reports the p-value for the test of whether the trend can be excluded from the cointegration space, $\mathrm{p}$ (co-trend). The final four columns report p-values from tests for GC from income to consumption $(p(y \underset{G C}{\rightarrow} c))$, GC from consumption to income $(p(c \overrightarrow{G C}) y)$, as well as tests for weak exogeneity of consumption, $\mathrm{p}(\mathrm{c}$ is WE), and income, $\mathrm{p}(\mathrm{y}$ is WE). 
Table A.4: Specification results for Midwest region for Great Moderation sample (1980q1-2007q4)

\begin{tabular}{|c|c|c|c|c|c|c|c|c|c|c|c|}
\hline MSA and state & Dum. & $p^{*}$ & $\operatorname{Rank}\left(\boldsymbol{\Pi}_{i}\right)$ & Auto. & Norm. & Hetero. & $\mathrm{p}($ co-trend $)$ & $p(y \underset{G C}{\overrightarrow{G C}} c)$ & $p(c \underset{G C}{\rightarrow} y)$ & $\mathrm{p}(\mathrm{c}$ is $\mathrm{WE})$ & $\mathrm{p}(\mathrm{c}$ is $\mathrm{WE})$ \\
\hline AKRON OH & 0 & 3 & 1 & 0 & 0.1377 & 0.8139 & 0.0002 & 0.1684 & 0.0254 & 0.0653 & 0.1242 \\
\hline ANN ARBOR MI & 0 & 5 & 0 & 1 & 0.3419 & 0.8928 & 0.1570 & 0.0110 & 0.1256 & 0.0021 & 0.1114 \\
\hline CHICAGO WI IN IL & 0 & 4 & 2 & 0 & 0.1082 & 0.1311 & 0.5330 & 0.0000 & 0.8818 & 0.0000 & 0.7957 \\
\hline CLEVELAND OH & 0 & 4 & 2 & 0 & 0.4411 & 0.5168 & 0.1051 & 0.0177 & 0.0025 & 0.0300 & 0.0111 \\
\hline DAYTON OH & 1 & 4 & 0 & 0 & 0.0226 & 0.6577 & 0.0149 & 0.0345 & 0.2404 & 0.0079 & 0.5621 \\
\hline DES MOINES IA & 1 & 5 & 1 & 0 & 0.1595 & 0.2998 & 0.0038 & 0.0003 & 0.0162 & 0.0000 & 0.8724 \\
\hline DETROIT MI & 0 & 4 & 0 & 0 & 0.3540 & 0.9846 & 0.0017 & 0.2744 & 0.0046 & 0.1555 & 0.0154 \\
\hline FARGO MN ND & 1 & 5 & 1 & 0 & 0.9356 & 0.0382 & 0.0009 & 0.7809 & 0.0657 & 0.4941 & 0.0020 \\
\hline FORT WAYNE IN & 1 & 4 & 0 & 1 & 0.1173 & 0.5895 & 0.6086 & 0.0007 & 0.8672 & 0.0003 & 0.4342 \\
\hline GARY IN & 0 & 4 & 2 & 0 & 0.2714 & 0.0794 & 0.0789 & 0.0000 & 0.1886 & 0.0000 & 0.3028 \\
\hline GRAND RAPIDS MI & 0 & 3 & 0 & 1 & 0.7150 & 0.3338 & 0.0028 & 0.2058 & 0.0018 & 0.8566 & 0.0174 \\
\hline INDIANAPOLIS IN & 0 & 5 & 1 & 0 & 0.9862 & 0.1262 & 0.0001 & 0.0110 & 0.0671 & 0.0010 & 0.9538 \\
\hline KANSAS CITY KS MO & 0 & 4 & 1 & 0 & 0.4910 & 0.9028 & 0.0095 & 0.0027 & 0.0919 & 0.0002 & 0.9667 \\
\hline LANSING MI & 1 & 2 & 0 & 0 & 0.5511 & 0.3432 & 0.0842 & 0.0202 & 0.0061 & 0.0234 & 0.2777 \\
\hline MADISON WI & 0 & 2 & 1 & 0 & 0.2247 & 0.7131 & 0.0063 & 0.0000 & 0.2793 & 0.0000 & 0.6037 \\
\hline MILWAUKEE WI & 0 & 4 & 1 & 0 & 0.8736 & 0.0210 & 0.0389 & 0.0016 & 0.0658 & 0.0001 & 0.1584 \\
\hline MINNEAPOLIS WI MN & 3 & 4 & 2 & 0 & 0.0075 & 0.1720 & 0.0075 & 0.0000 & 0.4557 & 0.0000 & 0.7257 \\
\hline OMAHA IA NE & 0 & 4 & 0 & 0 & 0.2370 & 0.7400 & 0.1922 & 0.0359 & 0.1608 & 0.0068 & 0.0843 \\
\hline PEORIA IL & 0 & 5 & 1 & 1 & 0.4766 & 0.1134 & 0.0000 & 0.0148 & 0.4096 & 0.0010 & 0.0842 \\
\hline ROCHESTER NY & 0 & 4 & 0 & 0 & 0.1926 & 0.2856 & 0.0741 & 0.1273 & 0.1892 & 0.0367 & 0.0432 \\
\hline ST LOUIS IL MO & 1 & 4 & 2 & 0 & 0.0104 & 0.4043 & 0.0032 & 0.0001 & 0.3360 & 0.0000 & 0.4472 \\
\hline SIOUX FALLS SD & 0 & 3 & 1 & 0 & 0.8063 & 0.0633 & 0.0003 & 0.0013 & 0.6812 & 0.0007 & 0.6976 \\
\hline SPRINGFIELD MA & 1 & 4 & 1 & 1 & 0.0663 & 0.6324 & 0.2196 & 0.1084 & 0.0108 & 0.0232 & 0.0204 \\
\hline TOLEDO OH & 0 & 4 & 2 & 0 & 0.1602 & 0.7262 & 0.0023 & 0.0051 & 0.0575 & 0.0010 & 0.1282 \\
\hline WICHITA KS & 1 & 4 & 2 & 0 & 0.2715 & 0.7638 & 0.0026 & 0.0010 & 0.7871 & 0.0001 & 0.7380 \\
\hline
\end{tabular}

Notes: This table reports supplementary results for the MSAs in our sample that are situated in the Midwest region of the US. The first three columns report the number of dummies picked up by the IIS algorithm, Dum., the selected lag length (based on AIC), $p_{i}^{*}$, and the cointegration rank, Rank ( $\Pi$ ). The next three columns report the p-value from tests for no autocorrelation (Auto.), normality (Norm.) and homoskedasticity (Hetero.). The next column reports the p-value for the test of whether the trend can be excluded from the cointegration space, $\mathrm{p}$ (co-trend). The final four columns report p-values from tests for GC from income to consumption $(p(y \overrightarrow{G C} c))$, GC from consumption to income $(p(c \underset{G C}{\rightarrow} y))$, as well as tests for weak exogeneity of consumption, $\mathrm{p}(\mathrm{c}$ is WE), and income, $\mathrm{p}(\mathrm{y}$ is WE).

Table A.5: Cointegration results for West region for Great Moderation sample (1980q1-2007q4)

\begin{tabular}{lccccccc}
\hline MSA and state & $\hat{\beta}_{y}^{I I S}$ & $s e\left(\hat{\beta}_{y}^{I I S}\right)$ & $\hat{\alpha}_{c}^{I I S}$ & $s e\left(\hat{\alpha}_{c}^{I I S}\right)$ & $\hat{\alpha}_{y}^{I I S}$ & $s e\left(\hat{\alpha}_{y}^{I I S}\right)$ & Likelihood \\
\hline ALBUQUERQUE NM & 0.9834 & 0.0311 & -0.1482 & 0.0414 & 0.0398 & 0.0331 & 684.5480 \\
BOISE CITY ID & 0.8978 & 0.0571 & -0.0774 & 0.0440 & 0.0311 & 0.0363 & 605.7252 \\
BOULDER CO & 0.6074 & 0.0514 & -0.0684 & 0.0383 & 0.0307 & 0.0340 & 631.4747 \\
COLORADO SPRINGS CO & 0.8030 & 0.0695 & -0.0508 & 0.0249 & 0.0308 & 0.0234 & 663.0202 \\
DENVER CO & 0.7619 & 0.0282 & -0.0846 & 0.0435 & 0.1037 & 0.0367 & 705.2742 \\
EUGENE OR & 0.6863 & 0.1310 & -0.0543 & 0.0199 & 0.0070 & 0.0149 & 646.6909 \\
HONOLULU HI & 0.7219 & 0.0918 & -0.1242 & 0.0422 & -0.0521 & 0.0303 & 685.0864 \\
LAS VEGAS NV & 1.0076 & 0.0278 & -0.1200 & 0.0277 & -0.0126 & 0.0231 & 649.4193 \\
LOS ANGELES CA & 1.0929 & 0.1234 & -0.0802 & 0.0277 & 0.0340 & 0.0232 & 673.1400 \\
OAKLAND CA & 0.5911 & 0.0471 & -0.2173 & 0.0579 & 0.0294 & 0.0472 & 677.7233 \\
OXNARD CA & 0.9251 & 0.0664 & -0.0702 & 0.0376 & 0.0639 & 0.0276 & 664.1026 \\
PHOENIX AR & 0.9544 & 0.0245 & -0.2199 & 0.0631 & -0.0261 & 0.0392 & 689.4353 \\
PORTLAND WA OR & 0.7904 & 0.0494 & -0.1096 & 0.0369 & 0.0383 & 0.0222 & 719.6856 \\
PROVO UT & 1.0822 & 0.0228 & -0.1781 & 0.0403 & 0.0287 & 0.0330 & 604.4709 \\
RIVERSIDE CA & 1.1702 & 0.0857 & -0.0242 & 0.0230 & 0.0472 & 0.0172 & 666.2857 \\
SACRAMENTO CA & 0.8133 & 0.0689 & -0.0601 & 0.0355 & 0.0349 & 0.0271 & 676.3557 \\
SALT LAKE CITY UT & 0.9708 & 0.0675 & -0.0293 & 0.0213 & 0.0547 & 0.0171 & 670.7926 \\
SAN DIEGO CA & 0.8308 & 0.0284 & -0.1824 & 0.0478 & 0.0542 & 0.0383 & 712.8950 \\
SAN FRANCISCO CA & 0.5336 & 0.0286 & -0.2625 & 0.0516 & -0.0428 & 0.0476 & 667.6387 \\
SAN JOSE CA & 0.6526 & 0.0563 & -0.1179 & 0.0336 & 0.0857 & 0.0368 & 640.7102 \\
SANTA ANA CA & 0.9094 & 0.0866 & -0.1075 & 0.0406 & 0.0089 & 0.0313 & 666.7492 \\
SEATTLE WA & 0.7700 & 0.0218 & -0.3364 & 0.0670 & 0.0406 & 0.0617 & 660.6230 \\
SPOKANE WA & 0.8239 & 0.0505 & -0.1738 & 0.0459 & 0.0194 & 0.0353 & 648.0029 \\
TACOMA WA & 0.7604 & 0.0469 & -0.1624 & 0.0391 & -0.0300 & 0.0304 & 655.0036 \\
TUCSON AZ & 0.7947 & 0.0524 & -0.1184 & 0.0377 & 0.0051 & 0.0292 & 671.6345 \\
\hline Notes Ti tan & & & & & &
\end{tabular}

Notes: This table reports the cointegration results for the MSAs in our sample that are situated in the West region of the US. The first column lists the name of the MSA, as well as the state it belongs to. The next six columns show the estimated long-run income elasticity and the speed of adjustment parameters, along with the estimated standard errors. The final column shows the likelihood. 
Table A.6: Cointegration results for East region for Great Moderation sample (1980q1-2007q4)

\begin{tabular}{lccccccc}
\hline MSA and state & $\hat{\beta}_{y}^{I I S}$ & $s e\left(\hat{\beta}_{y}^{I I S}\right)$ & $\hat{\alpha}_{c}^{I I S}$ & $s e\left(\hat{\alpha}_{c}^{I I S}\right)$ & $\hat{\alpha}_{y}^{I I S}$ & $s e\left(\hat{\alpha}_{y}^{I I S}\right)$ & Likelihood \\
\hline ALBANY NY & 0.7682 & 0.0661 & -0.1194 & 0.0269 & 0.0116 & 0.0364 & 622.4952 \\
BOSTON MA & 0.5016 & 0.0504 & -0.1695 & 0.0344 & -0.0482 & 0.0298 & 665.0053 \\
BRIDGEPORT CT & 0.6968 & 0.0394 & -0.1692 & 0.0415 & 0.0542 & 0.0386 & 640.7754 \\
BUFFALO NY & 1.2799 & 0.0502 & -0.2150 & 0.0478 & 0.0720 & 0.0519 & 662.5939 \\
CAMBDEN NJ & 1.0428 & 0.0689 & -0.0835 & 0.0374 & 0.0646 & 0.0292 & 643.4380 \\
EDISON NJ & 0.6962 & 0.0504 & -0.1352 & 0.0372 & 0.0304 & 0.0331 & 646.6993 \\
HARRISBURG PA & 1.1160 & 0.1153 & -0.0404 & 0.0212 & 0.0349 & 0.0152 & 691.4009 \\
HARTFORD CT & 0.3637 & 0.0958 & -0.1387 & 0.0296 & 0.0156 & 0.0242 & 618.4045 \\
MANCHESTER NH & 0.9299 & 0.0738 & -0.1086 & 0.0347 & 0.0357 & 0.0361 & 590.0464 \\
NASSAU NY & 0.8774 & 0.0621 & -0.1885 & 0.0434 & 0.0763 & 0.0535 & 647.3947 \\
NEWARK PA NJ & 0.4340 & 0.1005 & -0.1060 & 0.0332 & -0.0563 & 0.0262 & 670.3950 \\
NEW HAVEN CT & 0.7130 & 0.1290 & -0.0772 & 0.0346 & 0.0469 & 0.0260 & 601.2536 \\
NEW YORK NJ NY & 0.7690 & 0.0858 & -0.0762 & 0.0226 & 0.0508 & 0.0281 & 670.7662 \\
OCEAN CITY NJ & 0.4277 & 0.1539 & -0.0925 & 0.0272 & -0.0431 & 0.0228 & 514.6580 \\
PHILADELPHIA PA & 0.9665 & 0.0354 & -0.2224 & 0.0540 & 0.0694 & 0.0464 & 687.2860 \\
PITTSBURG PA & 0.9072 & 0.0630 & -0.1415 & 0.0482 & 0.1203 & 0.0432 & 703.7600 \\
PORTLAND ME & 0.4909 & 0.0877 & -0.1062 & 0.0301 & -0.0215 & 0.0204 & 599.2765 \\
PROVIDENCE MA RI & 0.8592 & 0.0683 & -0.1432 & 0.0306 & -0.0002 & 0.0243 & 689.7847 \\
SYRACUSE NY & 1.3850 & 0.0693 & -0.0870 & 0.0467 & 0.1595 & 0.0499 & 601.0707 \\
TRENTON NJ & 0.6473 & 0.0789 & -0.1261 & 0.0345 & 0.0043 & 0.0331 & 604.9171 \\
\hline
\end{tabular}

Notes: This table reports the cointegration results for the MSAs in our sample that are situated in the East region of the US. The first column lists the name of the MSA, as well as the state it belongs to. The next six columns show the estimated long-run income elasticity and the speed of adjustment parameters, along with the estimated standard errors. The final column shows the likelihood. 
Table A.7: Cointegration results for South region for Great Moderation sample (1980q1-2007q4)

\begin{tabular}{|c|c|c|c|c|c|c|c|}
\hline MSA and state & $\hat{\beta}_{y}^{I I S}$ & $\operatorname{se}\left(\hat{\beta}_{y}^{I I S}\right)$ & $\hat{\alpha}_{c}^{I I S}$ & $\operatorname{se}\left(\hat{\alpha}_{c}^{I I S}\right)$ & $\hat{\alpha}_{y}^{I I S}$ & $\operatorname{se}\left(\hat{\alpha}_{y}^{I I S}\right)$ & Likelihood \\
\hline ATLANTA GA & 0.7776 & 0.0216 & -0.2238 & 0.0417 & -0.0246 & 0.0287 & 679.2625 \\
\hline AUSTIN TX & 1.2799 & 0.0891 & -0.0088 & 0.0153 & 0.0341 & 0.0109 & 647.7250 \\
\hline BALTIMORE MD & 0.8584 & 0.0466 & -0.1629 & 0.0476 & 0.0831 & 0.0368 & 684.4944 \\
\hline BIRMINGHAM AL & 0.8846 & 0.0507 & -0.1197 & 0.0304 & 0.0339 & 0.0210 & 707.6373 \\
\hline CHARLOTTE SC NC & 0.8380 & 0.0332 & -0.1393 & 0.0409 & 0.0129 & 0.0296 & 682.6482 \\
\hline CINCINNATI IN KY OH & 0.7969 & 0.0516 & -0.1494 & 0.0408 & -0.0243 & 0.0316 & 701.4162 \\
\hline COLUMBUS OH & 1.2701 & 0.1483 & 0.0146 & 0.0219 & 0.0402 & 0.0141 & 550.5971 \\
\hline DALLAS TX & 0.6693 & 0.0242 & -0.1459 & 0.0558 & 0.0465 & 0.0441 & 696.8004 \\
\hline FORT LAUDERDALE FL & 1.1021 & 0.1009 & -0.0456 & 0.0377 & 0.0357 & 0.0273 & 694.3737 \\
\hline FORT WORTH TX & 1.6874 & 0.3959 & -0.0043 & 0.0172 & 0.0169 & 0.0138 & 665.2070 \\
\hline GREENSBORO I & 0.9670 & 0.0458 & -0.1250 & 0.0353 & 0.0228 & 0.0281 & 678.1753 \\
\hline GREENVILLE SC & 0.9753 & 0.0667 & -0.0361 & 0.0421 & 0.0559 & 0.0236 & 674.9334 \\
\hline HOUSTON TX & 0.6479 & 0.0222 & -0.1881 & 0.0472 & 0.0473 & 0.0438 & 684.7603 \\
\hline JACKSONVILLE FL & 0.9050 & 0.0322 & -0.1285 & 0.0435 & 0.0630 & 0.0358 & 684.3778 \\
\hline LITTLE ROCK AR & 1.8795 & 0.3536 & 0.0156 & 0.0073 & -0.0072 & 0.0054 & 673.6373 \\
\hline LOUISVILLE IN & 0.8410 & 0.0462 & -0.1536 & 85 & 0.00 & 0.0312 & 691.7986 \\
\hline MEMPHIS AR MS TN & 0.7607 & 0.0247 & -0.2275 & 0.0533 & -0.0053 & 0.0425 & 683.7340 \\
\hline MIAMI FL & -0.2010 & 0.5579 & -0.0139 & 0.0092 & -0.0095 & 0.0070 & 669.4106 \\
\hline NASHVILLE TN & 0.9105 & 0.0249 & -0.1939 & 0.0403 & 0.0037 & 0.0366 & 702.8282 \\
\hline NEW ORLEANS LA & 0.8231 & 0.0968 & -0.1674 & 0.0411 & 0.0 & 0.0329 & 676.1593 \\
\hline OKLAHOMA CIT & 0.7124 & 0.0992 & -0.0352 & 0.0288 & 0.0 & 0.0220 & 670.2655 \\
\hline ORLANDO FL & 0.9540 & 0.0491 & -0.1077 & 0.0352 & -0.0034 & 0.0293 & 677.6995 \\
\hline RALEIGH NC & 1.0119 & 0.0212 & -0.1449 & 0.0419 & 0.0524 & 0.0297 & 682.7069 \\
\hline RICHMOND VA & 1.0030 & 0.0515 & -0.0383 & 0.0314 & 0.1021 & 0.0219 & 691.3986 \\
\hline SAN ANTONIO TX & 0.9480 & 0.0472 & -0.0336 & 0.0293 & 0.0788 & 0.0249 & 697.3470 \\
\hline TAMPA FL & 0.3437 & 0.1802 & -0.0288 & 0.0110 & -0.0257 & 0.0090 & 683.5009 \\
\hline VIRGINIA BEACH NC VA & 0.7649 & 0.0561 & -0.1494 & 0.0317 & 0.0119 & 0.0300 & 648.5413 \\
\hline WASHINGTON WV MD VA & 0.7120 & 0.0256 & -0.2317 & 0.0449 & -0.0113 & 0.0361 & 701.1287 \\
\hline WEST PALM BEACH FL & 0.7911 & 0.0308 & -0.1210 & 0.0337 & 0.0479 & 0.0311 & 679.3454 \\
\hline WILMINGTON NJ MD DE & 0.9728 & 0.0343 & -0.2119 & 0.0439 & 0.0589 & 0.0363 & 669.8835 \\
\hline
\end{tabular}

Notes: This table reports the cointegration results for the MSAs in our sample that are situated in the South region of the US. The first column lists the name of the MSA, as well as the state it belongs to. The next six columns show the estimated long-run income elasticity and the speed of adjustment parameters, along with the estimated standard errors. The final column shows the likelihood. 
Table A.8: Cointegration results for Midwest region for Great Moderation sample (1980q1-2007q4)

\begin{tabular}{lccccccc}
\hline MSA and state & $\hat{\beta}_{y}^{I I S}$ & $s e\left(\hat{\beta}_{y}^{I I S}\right)$ & $\hat{\alpha}_{c}^{I I S}$ & $s e\left(\hat{\alpha}_{c}^{I I S}\right)$ & $\hat{\alpha}_{y}^{I I S}$ & $s e\left(\hat{\alpha}_{y}^{I I S}\right)$ & Likelihood \\
\hline AKRON OH & 1.0321 & 0.0777 & -0.0849 & 0.0477 & 0.0479 & 0.0324 & 675.4228 \\
ANN ARBOR MI & -0.1927 & 0.2789 & -0.0251 & 0.0086 & -0.0127 & 0.0086 & 593.2709 \\
CHICAGO WI IN IL & 0.7273 & 0.0268 & -0.3097 & 0.0574 & -0.0129 & 0.0527 & 683.4733 \\
CLEVELAND OH & 1.4354 & 0.1274 & -0.0592 & 0.0287 & 0.0563 & 0.0232 & 687.4960 \\
DAYTON OH & 1.0957 & 0.1640 & -0.0696 & 0.0275 & 0.0097 & 0.0178 & 683.2149 \\
DES MOINES IA & 0.6966 & 0.0451 & -0.1363 & 0.0329 & 0.0050 & 0.0334 & 670.7293 \\
DETROIT MI & -11.8396 & 4.7449 & -0.0049 & 0.0037 & -0.0077 & 0.0033 & 647.8484 \\
FARGO MN ND & 0.9646 & 0.0641 & 0.0276 & 0.0451 & 0.1933 & 0.0678 & 481.7431 \\
FORT WAYNE IN & 0.4036 & 0.0867 & -0.0667 & 0.0193 & -0.0113 & 0.0154 & 675.1286 \\
GARY IN & 1.0307 & 0.0296 & -0.3057 & 0.0531 & 0.0452 & 0.0464 & 666.5616 \\
GRAND RAPIDS MI & 1.1502 & 0.0930 & 0.0057 & 0.0330 & 0.0645 & 0.0280 & 645.6913 \\
INDIANAPOLIS IN & 0.8024 & 0.0507 & -0.1090 & 0.0348 & -0.0016 & 0.0298 & 676.8026 \\
KANSAS CITY KS MO & 0.7418 & 0.0686 & -0.1187 & 0.0322 & 0.0009 & 0.0224 & 702.5573 \\
LANSING MI & -0.2340 & 0.4613 & -0.0206 & 0.0093 & -0.0087 & 0.0093 & 640.4061 \\
MADISON WI & 0.4818 & 0.1096 & -0.0555 & 0.0119 & -0.0047 & 0.0093 & 638.5430 \\
MILWAUKEE WI & 0.4492 & 0.0737 & -0.1098 & 0.0278 & 0.0319 & 0.0239 & 688.6969 \\
MINNEAPOLIS WI MN & 0.6770 & 0.0563 & -0.1084 & 0.0255 & -0.0084 & 0.0259 & 672.9606 \\
OMAHA IA NE & 0.8976 & 0.0549 & -0.0893 & 0.0345 & 0.0485 & 0.0296 & 668.0966 \\
PEORIA IL & 0.7689 & 0.0644 & -0.1544 & 0.0494 & 0.0635 & 0.0394 & 663.1911 \\
ROCHESTER NY & 0.9590 & 0.1295 & -0.0701 & 0.0356 & 0.0866 & 0.0454 & 553.3168 \\
ST LOUIS IL MO & 0.9108 & 0.0311 & -0.2708 & 0.0625 & 0.0371 & 0.0521 & 703.3568 \\
SIOUX FALLS SD & -0.4197 & 0.3355 & -0.0205 & 0.0062 & 0.0028 & 0.0076 & 483.9687 \\
SPRINGFIELD MA & 0.9553 & 0.2310 & -0.0467 & 0.0219 & 0.0372 & 0.0171 & 565.0260 \\
TOLEDO OH & 1.1075 & 0.0816 & -0.1247 & 0.0392 & 0.0447 & 0.0311 & 679.7043 \\
WICHITA KS & 0.8099 & 0.0555 & -0.1756 & 0.0466 & 0.0111 & 0.0352 & 667.3760 \\
\hline
\end{tabular}

Notes: This table reports the cointegration results for the MSAs in our sample that are situated in the Midwest region of the US. The first column lists the name of the MSA, as well as the state it belongs to. The next six columns show the estimated long-run income elasticity and the speed of adjustment parameters, along with the estimated standard errors. The final column shows the likelihood. 